\title{
Niveles marinos en Jaizkibel: interpretación sedimentaria y dinámica geomorfológica cuaternaria
}

\author{
Jaizkibeleko itsas-mailak: Kuaternarioko sedimentuen eta \\ dinamika geomorfologikoaren interpretazioa
}

\section{Quaternary sea level changes in Jaizkibel: Sedimentary interpretation and geomorphological dynamics}

\author{
Jose M. Edeso ${ }^{1 *}$, Ane Lopetegi ${ }^{1}$, Jose A. Mujika ${ }^{2}$ \\ ${ }_{1}^{1}$ Escuela Universitaria de Ingeniería de Vitoria-Gasteiz (E.U.I.), UPV-EHU, Nieves Cano 12, 01006 Vitoria-Gasteiz. \\ ${ }^{2}$ Facultad de Letras de Vitoria-Gasteiz, UPV-EHU, Tomás y Valiente s/n, 01006 Vitoria-Gasteiz. \\ *Correspondencia: josemiguel.edeso@ehu.es
}

\section{RESUMEN}

A lo largo del relieve en cuesta de Jaizkibel se desarrollan 3 niveles marinos situados a distintas altitudes respecto a la línea de costa actual. El más alto se localiza entre 220 y 250 m identificándose con una plataforma erosiva (rasa mareal), sin depósitos correlativos asociados que bisela las areniscas y calizas arenosas del Eoceno inferior. No existen criterios de datación absoluta por lo que su cronología debe situarse en algún momento del Pleistoceno Inferior o del Plioceno. Un segundo nivel se desarrolla entre los 30 y $40 \mathrm{~m}$, justo por encima del acantilado actual. Este nivel tiene depósitos asociados y está fosilizado a su vez por una potente acumulación areno-limosa de cronología Tardiglaciar. A una altura similar se localiza, en el frente del monoclinal, el depósito de Goizut, que puede interpretarse como una paleodesembocadura de edad Pleistocena. Por último, entre 1 y $2 \mathrm{~m}$ por encima del máximo nivel alcanzado por la pleamar actual, se desarrollan una serie de formas erosivas y niveles de acumulación de edad holocena (540-690 AD) que señalan la presencia de un nivel marino transgresivo situado por encima del $0 \mathrm{~m}$ actual.

PALABRAS CLAVE: Depósitos correlativos, Holoceno, paleodesembocadura, Pleistoceno, rasas, transgresión.

\section{LABURPENA}

Jaizkibelgo monoklinalean zehar egungo itsas lerroaren arabera garaiera ezberdinetara gelditzen diren 3 itsas maila garatzen dira. Garaiena 220 m eta 250 m bitartean kokatzen da, Behe Eozenoko hareharri eta kareharri hondartsuak lantzerka ahopiltzen dituen higadura-plataforma (itsas laugune) batean identifikatzen da, nahiz eta berarekin korrelazioan egon daitekeen metaketarik ez gelditu. Bere datazio absoluturako irizpiderik ez dagoenez Behe Pleistozenoko edo Pliozenoko une batean koka daitezke. Bigarren maila bat 30 eta 40 metro bitartean kokatzen da, egungo labarraren gainean hain justu. Maila honek baditu metaketak eta gainera Izoztaro Berantiarreko hondar-lohi metaketa lodi batek fosilizatzen du. Antzeko altueran, monoklinalaren frontean, Pleistozenoko paleobokale gisa interpretatu daiteken Goizuteko metaketa kokatzen da. Azkenik, egungo itsasgorako aldi gorenena baino 1 eta 2 m gorago agertzen diren Holozenoko (540-690 AD) higadura-formak eta metaketa-mailak adierazten dute egungo 0 mailaren gainetik itsas-maila transgresibo bat dagoela.

GAKO-HITZAK: Depositu korrelatiboak, Holozeno, itsas lauguneak, paleobokale, Pleistozeno, transgresio.

\section{ABSTRACT}

Throughout Jaizkibel monoclinal relief, three different sea level evidences can be observed at different altitudes compared to present sea level. The highest one is a naked abrasion platform without correlative deposits, which is located between 220 and $250 \mathrm{~m}$ above current sea level. This erosive form, modelled by wave energy, cuts the lower Eocene sandstone and limestone strata of the monoclinal. The absence of correlative deposits does not allow for absolute dating, but its age can be estimated sometime between lower Pleistocene and Pliocene. A second level lies between 30 and $40 \mathrm{~m}$, just above the current cliff. This abrasion platform does have correlative deposits ; moreover, both platform and deposits were in turn fossilized due to a large accumulation of Late Glacial age sandy-loamy sediment. The Goizut deposit is located at a similar raise in the front of the monoclinal, which can be interpreted as a Pleistocene age river paleomouth. Finally, between 1 and $2 \mathrm{~m}$ above the highest level reached by the present tide, lie a series of erosive forms and sediments of Holocene age ( $540-690$ AD ) indicating the presence of a third transgressive sea level.

KEY WORDS: Abrasion platform, correlative deposits, Holocene, paleo rivermouth, Pleistocene, transgression

\section{INTRODUCCIÓN}

El monoclinal de Jaizkibel (Fig. 1) se desarrolla entre los estuarios del Bidasoa y del Oiartzun-Bahía de Pasajes, configurando una pequeña alineación montañosa de dirección general NE-SO que culmina en el monte Allerru, Jaizkibel o San Enrique a $547 \mathrm{~m}$ de altitud. Forma parte de la Cadena Terciaria Costera (Unidad de San Sebastián) que se extiende desde el Cabo Higer hasta la punta de San Antón en Getaria.
Centrándonos exclusivamente en los trabajos de índole geomorfológica vinculados con el monoclinal de Jaizkibel, y dejando de lado las aportaciones de Llarena (1960) sobre las formas marinas actuales existentes en el litoral guipuzcoano, podemos afirmar que los primeros trabajos que abordan cuestiones geomorfológicas son los efectuados por Rómulo Santana (1966) en su tesis doctoral titulada "Géomorphologie des bassins de la Bidasoa et de l'Urumea". Tras 


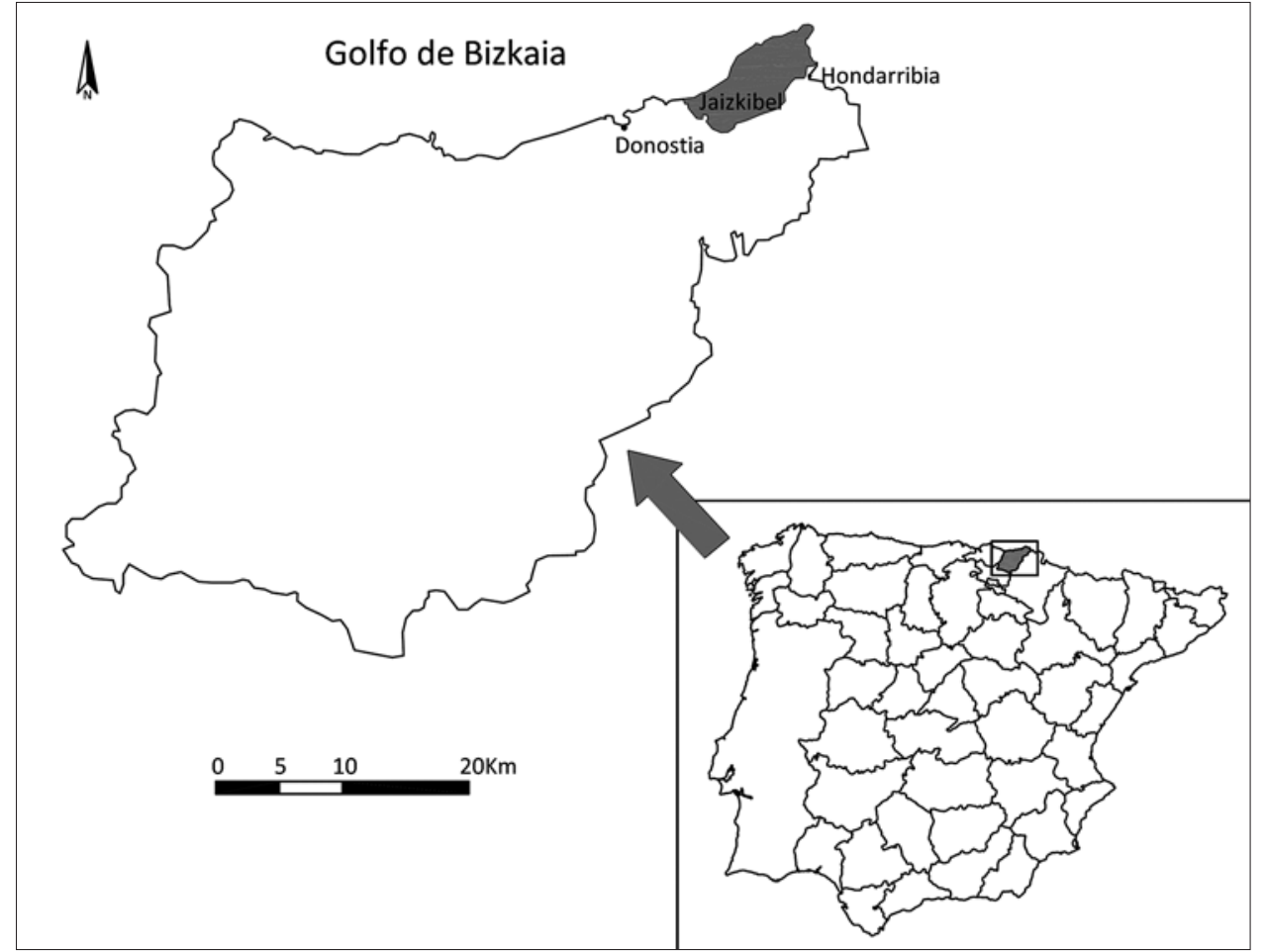

Fig. 1. - Localización de la zona de estudio

1. Irudia. Aztergai den eremuaren kokapena. él se abre un largo período de olvido, que se prolongará hasta finales de la década de los 80 principios de los 90. En estos momentos se inician una serie de prospecciones geomorfológicas (en el marco de una nueva tesis doctoral) que cristalizan en una serie de publicaciones de la mano de Ugarte \& Edeso (1987), Edeso \& Ugarte (1990), Cearreta et al. (1992) y Edeso (1990, 1991, 1992, 1994), las cuales abordan el análisis y caracterización de diversas formas y depósitos marinos localizados en el monoclinal y en el entorno inmediato (depósitos actuales, plataformas de abrasión de Marla, Turrulla, Iturriointxo, depósitos de Goizut, Manziategi, Irubide y Anzaran).

A partir del año 2000 se realizan algunos intentos de síntesis Cuaternaria (Edeso \& Mujika, 2005; González et al., 2005), así como nuevos descubrimientos (Lopetegi et al., 2012), algunos de los cuales están en proceso de estudio y evaluación en estos momentos. Una parte significativa de la información disponible va a quedar recogida en la presente monografía, aunque algunos de los aspectos aquí registrados son sin duda novedosos.

El objetivo del presente trabajo es determinar la presencia de antiguos niveles marinos (pleistocenos y holocenos) en el monoclinal de Jaizkibel, con el fin de aportar información sobre las variaciones experimentadas por el nivel del mar (o por el margen continental) a lo largo del Cuaternario.

\section{MATERIAL Y MÉTODOS}

\section{Marco morfo-estructural}

Litológicamente, el monoclinal está constituido por una potente sucesión terrígena (formación Higer-Getaria) (Pu- jalte et al., 2000; Gibbons, 2002; Hodgson, 2006) integrada por dos litologías distintas. La primera está formada por gruesos bancos de arenisca cuarzosa de grano fino a medio (en paquetes estrato y granocrecientes), que hacia el techo pasan a arenas gruesas y/o microconglomerados (Garrote et al., 1990). Tienen cemento calcáreo siendo su tonalidad gris azulada en corte fresco y amarilla naranja a parda por alteración. El segundo conjunto está constituido por una alternancia de calizas arenosas, lutitas (menos del $20 \%$ ) y areniscas en delgados niveles no cartografiables (Fig. 2). Su edad es Eoceno inferior.

Tal y como hemos señalado anteriormente, la alineación del monte Jaizkibel se define como un relieve monoclinal del tipo cuesta y/o cresta, cuyo frente domina mediante un escarpe vertical de $300 \mathrm{~m}$ de altitud el valle ortoclinal Irún-San Sebastián (Edeso, 1990). Este frente únicamente se ve alterado por una serie de cursos anaclinales, -normalmente secos-, de trazado rectilíneo que se disponen siguiendo la línea de máxima pendiente.

El dorso del monoclinal configura un relieve estructural abrupto y escarpado, incidido por una serie de cursos cataclinales y ortoclinales de reverso, de fuerte pendiente y de marcado carácter torrencial. La acusada diversidad litológica, geomorfológica y morfotopográfica, nos permite diferenciar dos sectores de características contrastadas: el sector oriental y el sector occidental (Fig. 3).

El sector oriental engloba el espacio comprendido entre el Cabo Higer y punta Turruia (Fig. 3). Predominan las calizas arenosas con valores de buzamiento que oscilan entre 20 y $25^{\circ}$ lo que determina el desarrollo de un relieve del tipo cuesta. Los diversos valles fluvio-torrenciales que drenan el dorso del monoclinal, inscriben sus 


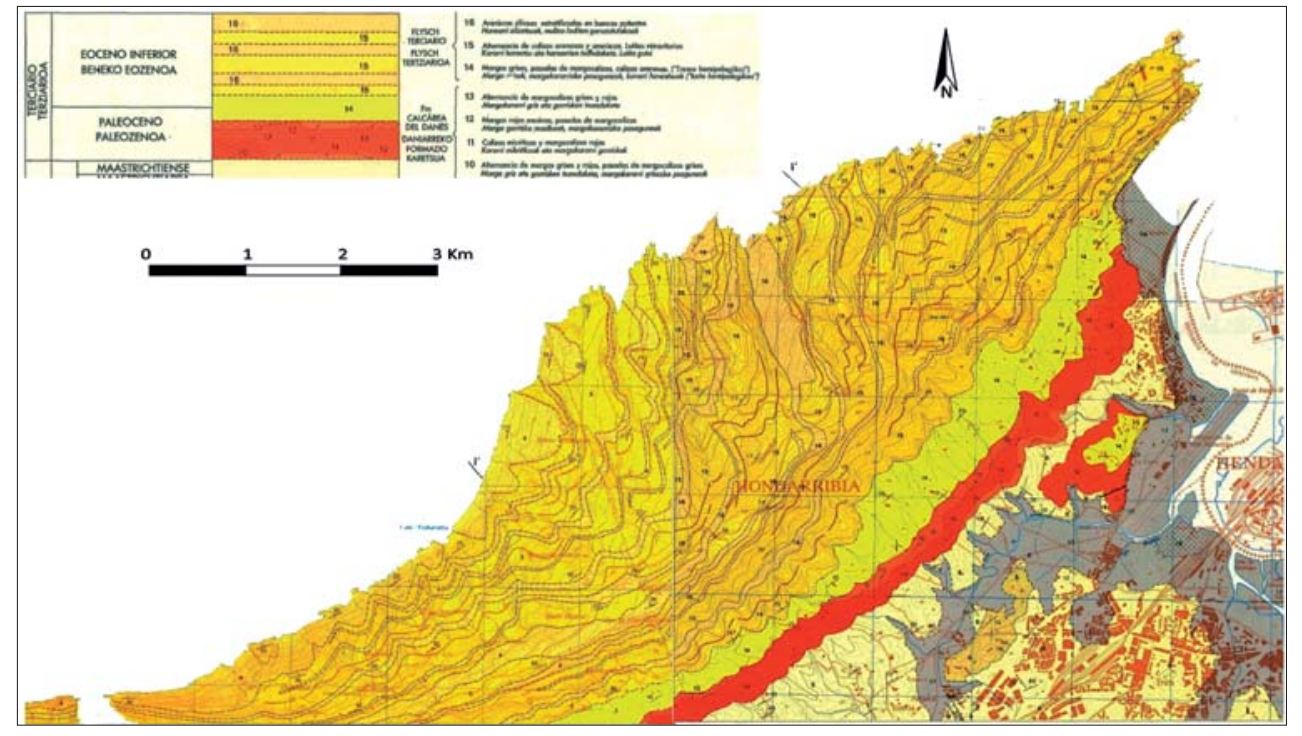

Fig. 2. - Mapa Geológico de Jaizkibel. Fuente: Garrote et al., 1990 2. Irudia. Jaizkibelgo Mapa Geologikoa (Garrote et al., 1990).

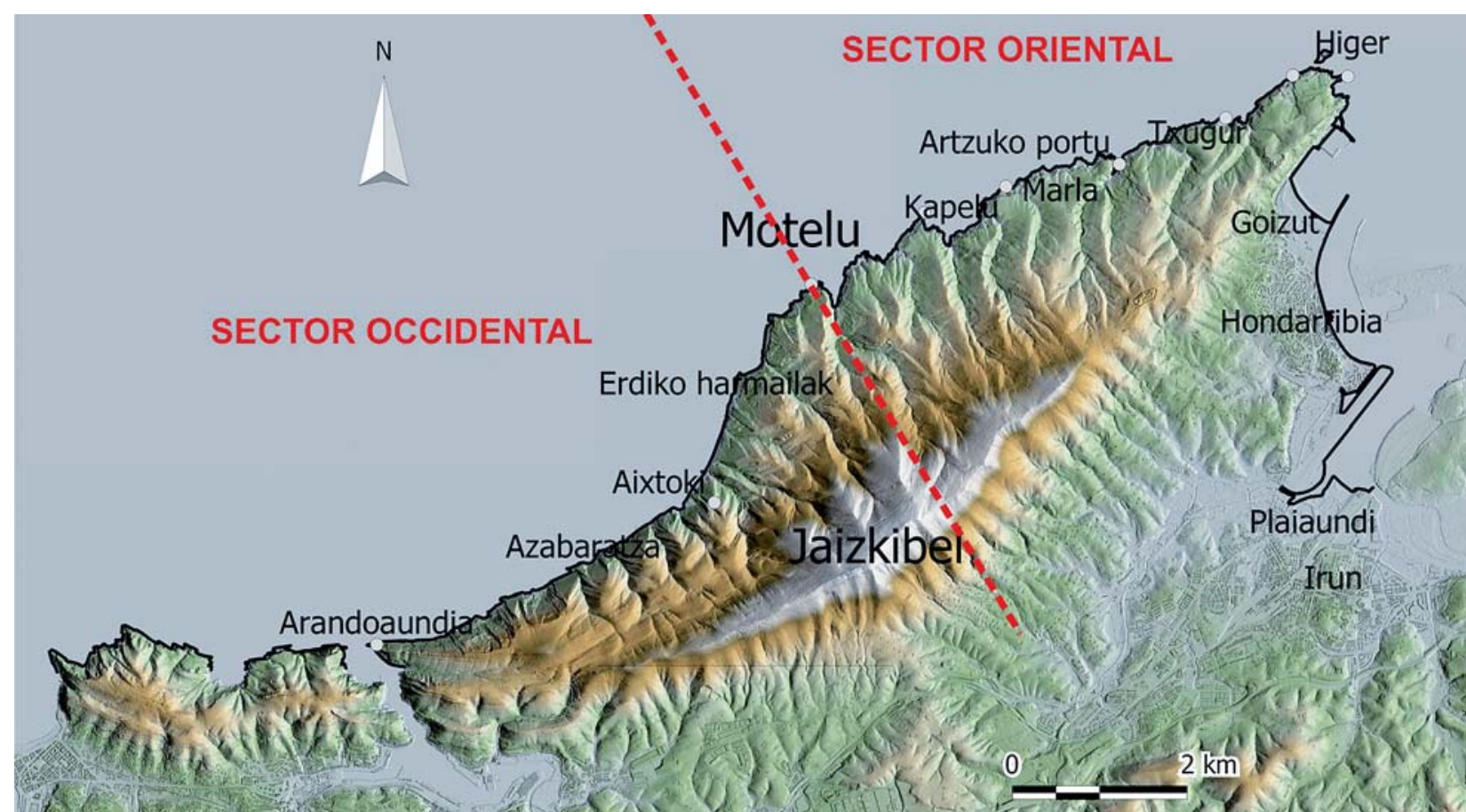

Fig. 3. - Modelo Digital del Terreno de Jaizkibel. Podemos observar como en el sector oriental se desarrollan numerosas calas y entrantes (costa más recortada modelada sobre calizas arenosas), mientras que en el occidental predominan los trazados rectilineos (areniscas silíceas). El primero se extiende desde el Cabo Higer hasta Motelu, mientras que el segundo se prolonga desde ese punto hasta la bahía de Pasajes.

3. Irudia. Jaizkibelgo Lur Eredu Digitala. Ekialdeko aldean, senaia txiki eta sartune ugari (kareharri hondartsuetan moldatutako itsasertza) dauden bitartean mendebaldekoan nola lerrozuzenak dituen (silizedun hareharriak) ikus daiteke. Lehenengo eremua Higer lurmuturra eta Motelu artean kokatzen da eta bigarrena Motelutik Pasaiako badiaraino.

cauces aprovechando los contactos litológicos entre las calizas arenosas y las areniscas silíceas, lo que determina el modelado (por erosión diferencial) de una serie de valles disimétricos (Fig. 4), con una vertiente occidental (areniscas silíceas) dominada por un escarpe vertical/subvertical y otra oriental más suave y tendida, modelada sobre las calizas arenosas.

El desarrollo de la línea de costa también está condicionado por la litología, ya que las calizas arenosas presentan una menor resistencia a la erosión que las areniscas silíceas, lo que ha favorecido su desmantelamiento erosivo y el modelado de una serie de calas y ensenadas de tamaño diverso (Kazkalleta, Baxuko Badia, Artzuko Portu, Limaputzu, Xixurko, Aingiraputzu, Erantzintxiki, Erantzinaundi), mientras que los materiales duros favorecen el desarrollo de diversos salientes (Arregi, Biosnar, Urillo, Kapelu, Abillu, Gaztarri, Lapuntta, Amuaitz...) o de tramos rectilíneos. Los cursos fluvio-to- 


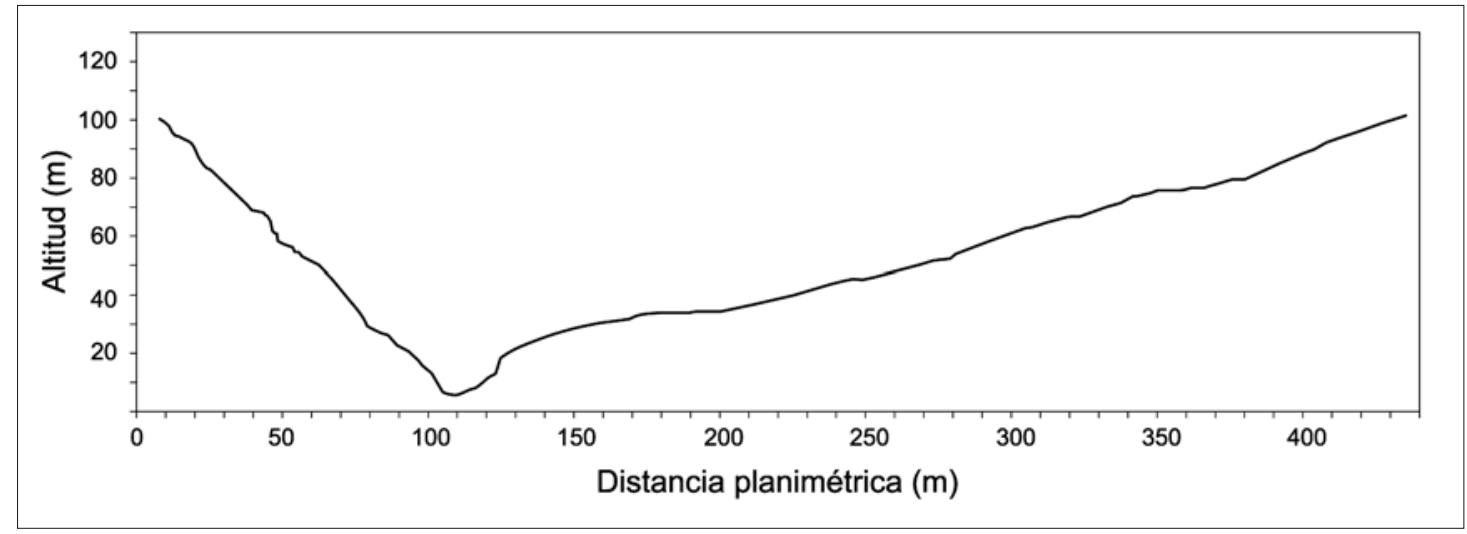

Fig. 4. - Perfi transversal del curso cataclinal Zezentegietako erreka.

4. Irudia. Zezentegietako Errekako ibilbide kataklinaleko zeharkako profila.

rrenciales que drenan estos espacios alcanzan la línea de costa de dos maneras diferentes; los de menor importancia lo hacen mediante un salto vertical/subvertical que puede superar los $10 \mathrm{~m}$ de altura, mientras que los cursos más importantes (Erramudika erreka, Txortxipiko erreka, Martitxerreka, Zezentegietako erreka...) presentan un pequeño salto vertical (entre 1 y 2 metros $^{1}$ ) varios cientos de metros antes de desembocar en el mar.

El sector occidental se extiende desde la bocana del puerto de Pasajes hasta Punta Turruia (Fig. 3). En este tramo predominan las areniscas silíceas, lo que determina el modelado de un relieve monoclinal del tipo crestas y barras (Edeso, 1990), muy abrupto y escarpado (los valores de buzamiento se incrementan paulatinamente de E a W llegando a ser subverticales en Puntas de San Juan y en el Faro de la Plata). La incisión de la red hidrográfica determina el modelado de grandes chevrones separados por valles en V (Fig. 5), profundamente encajados que alcanzan el nivel del mar mediante una serie de saltos subverticales de entre 10 y 20 metros de desnivel. La costa es claramente rectilínea, configurando un muro continuo (el único accidente digno de mención es la cala de Azabaratza modelada a expensas de las calizas arenosas) a cuyos pies se desarrolla una exigua plataforma de abrasión marina.

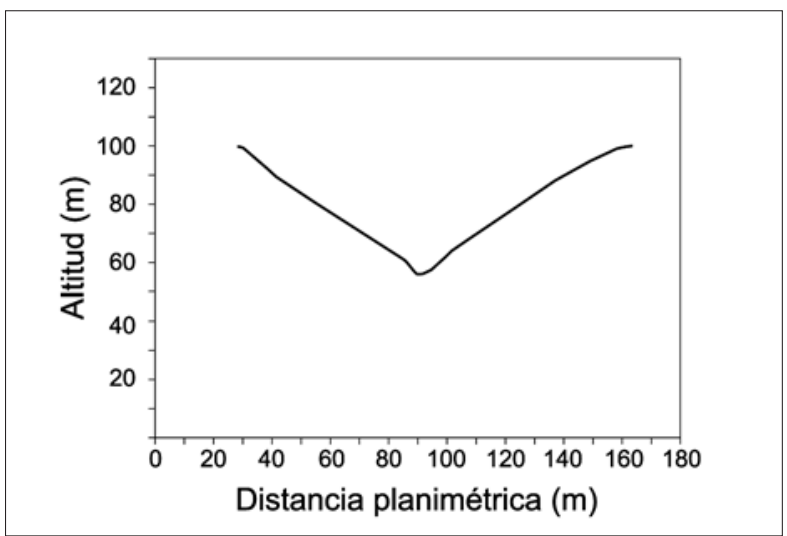

Fig. 5. - Perfil transversal del curso cataclinal Arangua Erreka. 5. Irudia. Arangua Errekako ibilbide kataklinaleko zeharkako profila.

\section{Métodos de estudio}

Para determinar la presencia de antiguos niveles marinos (pleistocenos y holocenos) en el monoclinal de Jaizkibel hemos efectuado una minuciosa prospección del territorio, inventariando las distintas formas y depósitos encontrados, procediendo posteriormente a su descripción geomorfológica (altura, dimensiones, potencia, morfología, etc.) y a su cartografía, utilizando para ello tanto Sistemas de Posicionamiento Global, como tecnología SIG.

Posteriormente hemos realizado un muestreo exhaustivo de los depósitos, con el fin de determinar la granulometría, tanto de la fracción gruesa (índice de rodamiento, aplanamiento, distribución por intervalos) como de la fina (tamizaje en seco, morfoscopía de la fracción arenosa, densimetría) (Cailleux, 1959; Folk \& Ward, 1957), la composición litológica y, en algunos casos, la mineralogía de las arenas. También se han tomado muestras para efectuar el análisis palinológico y micropaleontológico de las acumulaciones más significativas, pero la elevada acidez del medio, junto con la antigüedad de los depósitos, ha hecho que los resultados hayan sido improductivos. En la mayor parte de los casos tampoco ha sido posible efectuar dataciones absolutas debido a la falta de evidencias susceptibles de ser datadas. Tampoco ha sido posible datar estas evidencias mediante Luminiscencia Ópticamente Estimulada (OSL) ya que en unos casos el muestreo se efectuó antes del desarrollo de la técnica (actualmente se ha construido encima) y en otros presentaban diversos problemas de contaminación natural, lo que desvirtuaba la edad de la acumulación. Únicamente en los depósitos más recientes (Holocenos) se ha podido establecer una cronología precisa. En el resto de los niveles nos vemos obligados a especular y a buscar paralelismos con acumulaciones o formas erosivas similares, localizadas en otros ámbitos territoriales.

\section{RESULTADOS}

Uno de los enclaves guipuzcoanos en los que mejor se han conservado las evidencias marinas pliocenas/pleistocenas (no así las holocenas) es el monoclinal del Jaizkibel, dónde hemos podido cartografiar dos niveles de

\footnotetext{
${ }^{1}$ La única excepción la constituye Erramudiko erreka que presenta un salto de más de $6 \mathrm{~m}$.
} 
rasas, un depósito poligénico y una serie de formas erosivas y niveles de acumulación de edad reciente.

\section{Depósitos Pleistocenos}

Las evidencias marinas existentes a lo largo del monoclinal (Fig. 6) están representadas por sendas plataformas de abrasión marina o rasas mareales, con o sin depósitos correlativos, y por el depósito de Goizut (Hondarribia). En el primer caso se han localizado dos niveles colgados a distintas alturas (220-250 m y 30-40 m) respecto al 0 actual y en el segundo se trata de una paleodesembocadura compleja, situada a una altitud similar a la que presentan las rasas.

\section{Plataforma de abrasión o rasa mareal situada a 220-250 m}

Configura un nivel discontinuo sumamente desmantelado por la acción erosiva de los cursos cataclinales del Jaizkibel. Se ha conservado, casi exclusivamente, en el sector occidental del monoclinal configurando una plataforma horizontal (a veces algo deformada) que se dispone inclinada $\left(>5^{\circ}\right)$ hacia el mar (Fig. 6 y 7). No se han encontrado depósitos correlativos, desarrollándose sobre ella un exiguo suelo areno-limoso muy rico en materia orgánica. La ausencia de depósitos marinos junto con la inexistencia de otras evidencias morfológicas no nos permite descartar taxativamente el origen continental de la superficie, aunque su posición, su morfología y su pendiente longitudinal y transversal, apuntan hacia un modelado vinculado a un ambiente litoral de costa abierta batida por el oleaje (su posición altimétrica actual es el resultado de elevación acaecidos a lo largo de Pleistoceno). Además, su dispositivo morfotopográfico y la ausencia de este tipo de morfologías en el ámbito de la comunidad (sobre todo al norte de la divisoria de aguas cantábrico-mediterránea) apuntan hacia un origen marino.

\section{Plataformas de abrasión o rasas mareales situadas a 30-40 m}

Este nivel se desarrolla entre Motelu (punta Arregi) y el Cabo Higer (Hondarribia), es decir, en el sector oriental del monoclinal. El análisis batimétrico nos sugiere que el retroceso de la línea de costa ha sido mayor en el sector occidental que en el oriental, lo que explicaría la destrucción de las rasas y su ausencia en esta zona.

Estos vestigios se localizan a lo largo de la línea de costa, justo por encima del borde del acantilado actual, a unos 30-40 metros de altitud² (Fig. 6, 8 y 9). Configuran una plataforma erosiva de extensión y anchura variable (sus dimensiones oscilan entre unas decenas y varios centenares de metros) que ha sido modelada a expensas de las calizas arenosas (y en menor medida de las areniscas silíceas) de la formación Higer-Getaria.

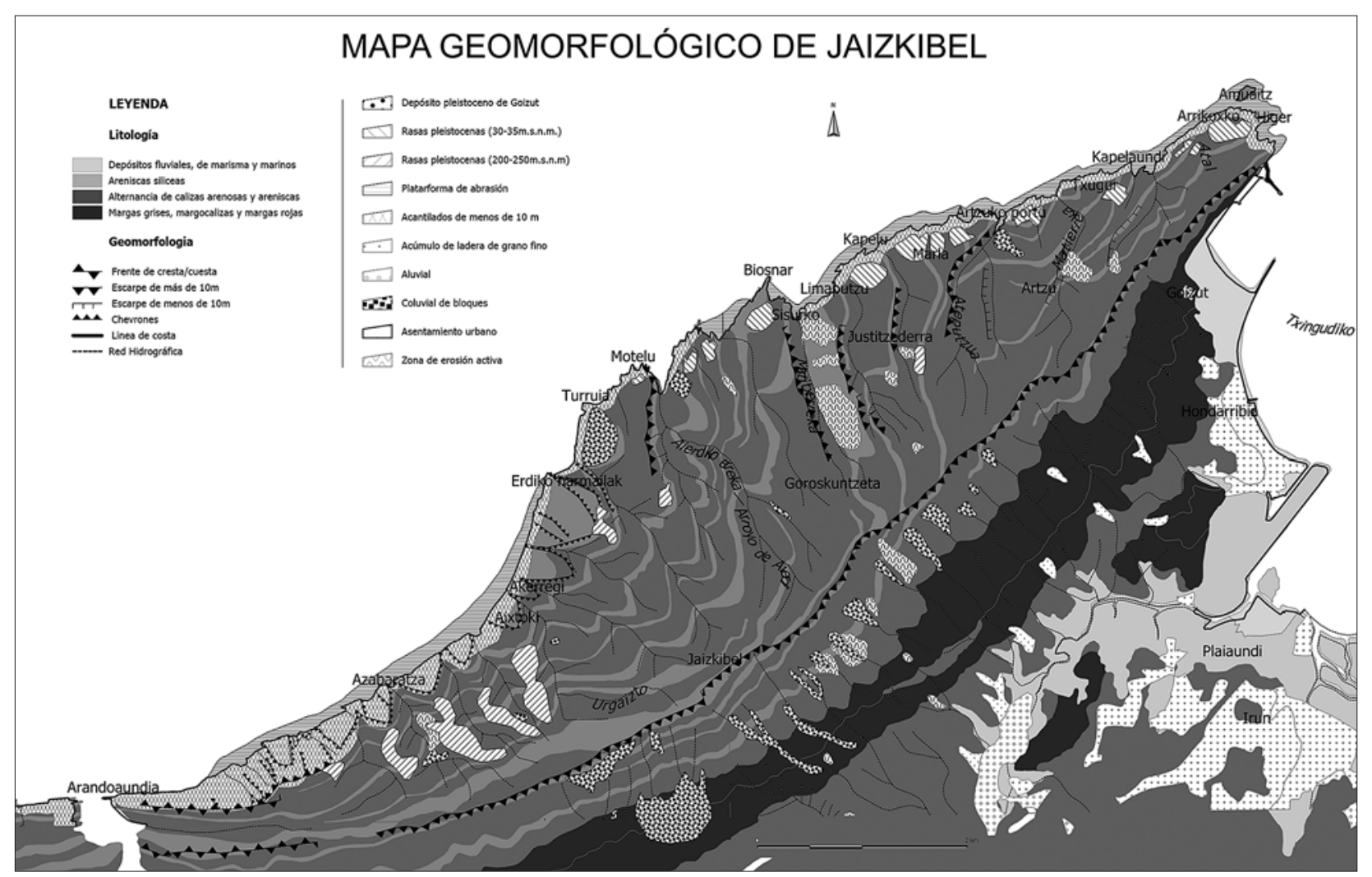

Fig. 6. - Mapa geomorfológico del monoclinal de Jaizkibel.

6. Irudia. Jaizkibel monoklinaleko mapa geomorfologikoa. 


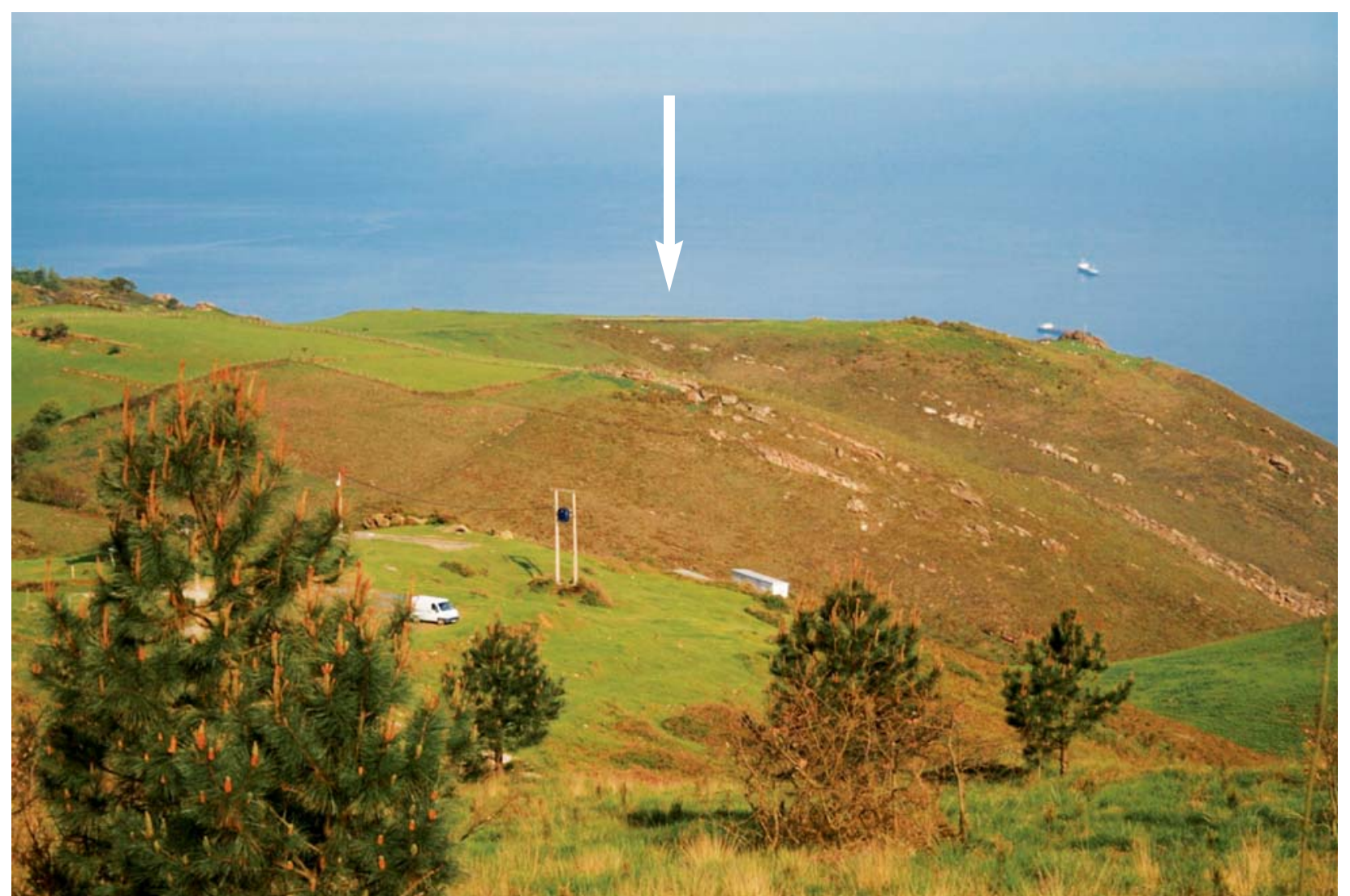

Fig. 7. - Nivel de rasa situado entre los 220 y los $250 \mathrm{~m}$

7. Irudia. 220 eta 250 metro tartean kokatzen den itsas laugune-maila.

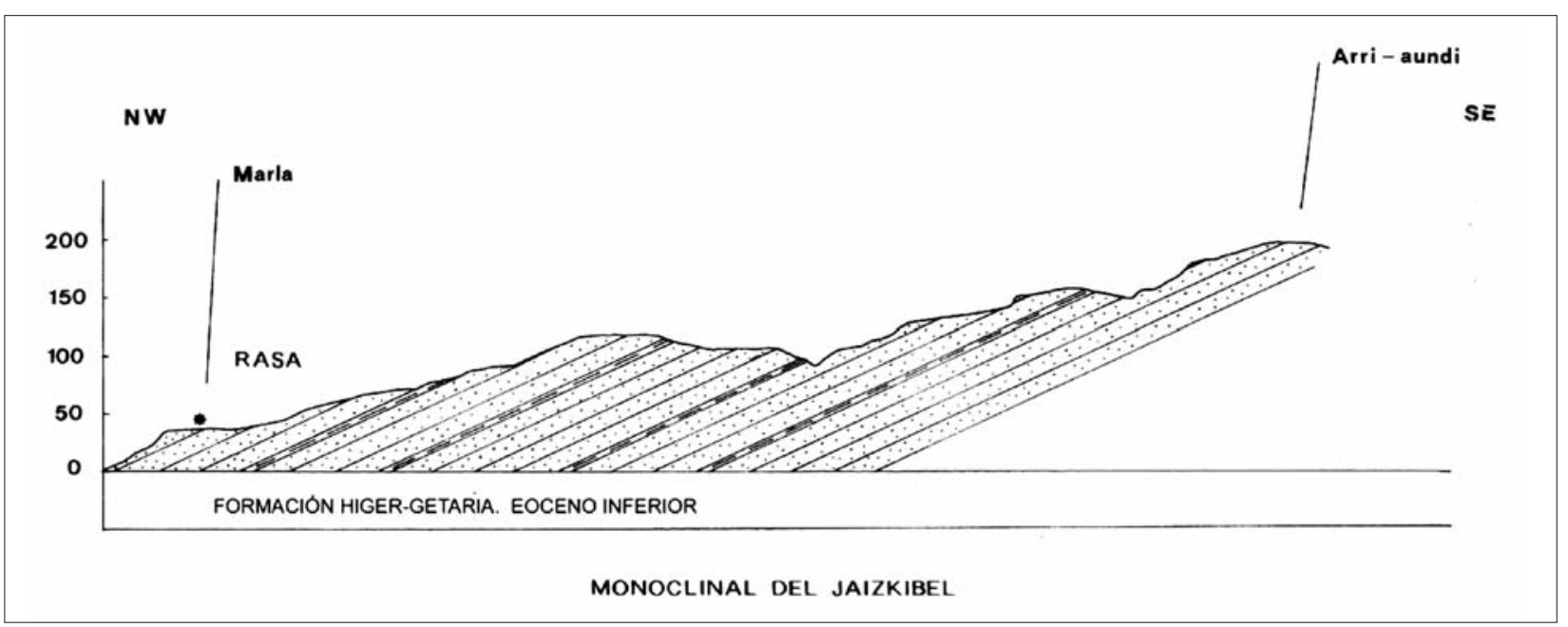

Fig. 8. - Perfil longitudinal del monoclinal de Jaizkibel entre los parajes de Marla y Arri-Aundi (Edeso, 1991).

8. Irudia. 220 eta 250 metro tartean kokatzen den itsas laugune-maila.

Morfológicamente se identifican con una superficie subhorizontal (1 ó $2^{\circ}$ ), inclinada hacia el mar (Fig. 12 y 13), que ha sido parcialmente desmantelada por la incisión de los numerosos cursos cataclinales que drenan el dorso del monoclinal y por el retroceso experimentado por la línea de costa a lo largo del Pleistoceno y Holoceno. El primitivo nivel ha quedado reducido a una serie de retazos discontinuos entre los que destacan los localizados en Biosnar, Txortxipi, Marla y Cabo Higer. Aunque no todos los afloramientos tienen la misma estratigrafía (algunos sólo muestran una película de cantos y gravas recubiertas por un delgado suelo), los perfiles más completos presentan, de muro a techo, la siguiente secuencia (Fig. 10 y 11): 


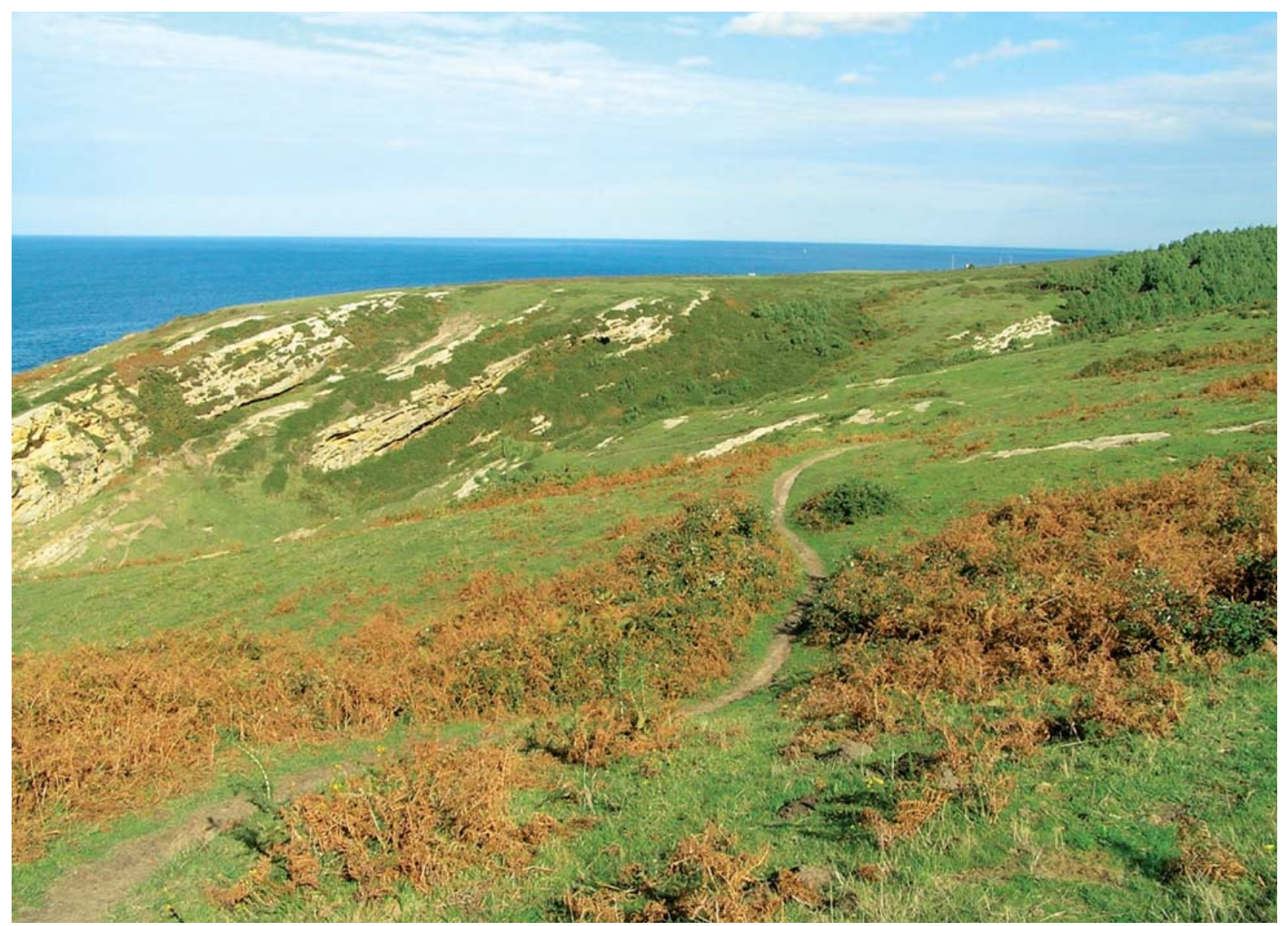

Fig. 9. - Vista general de la plataforma de abrasión de Txortxipi.

9. Irudia. Txortxipiko urradura-plataformako ikuspegi orokorra.

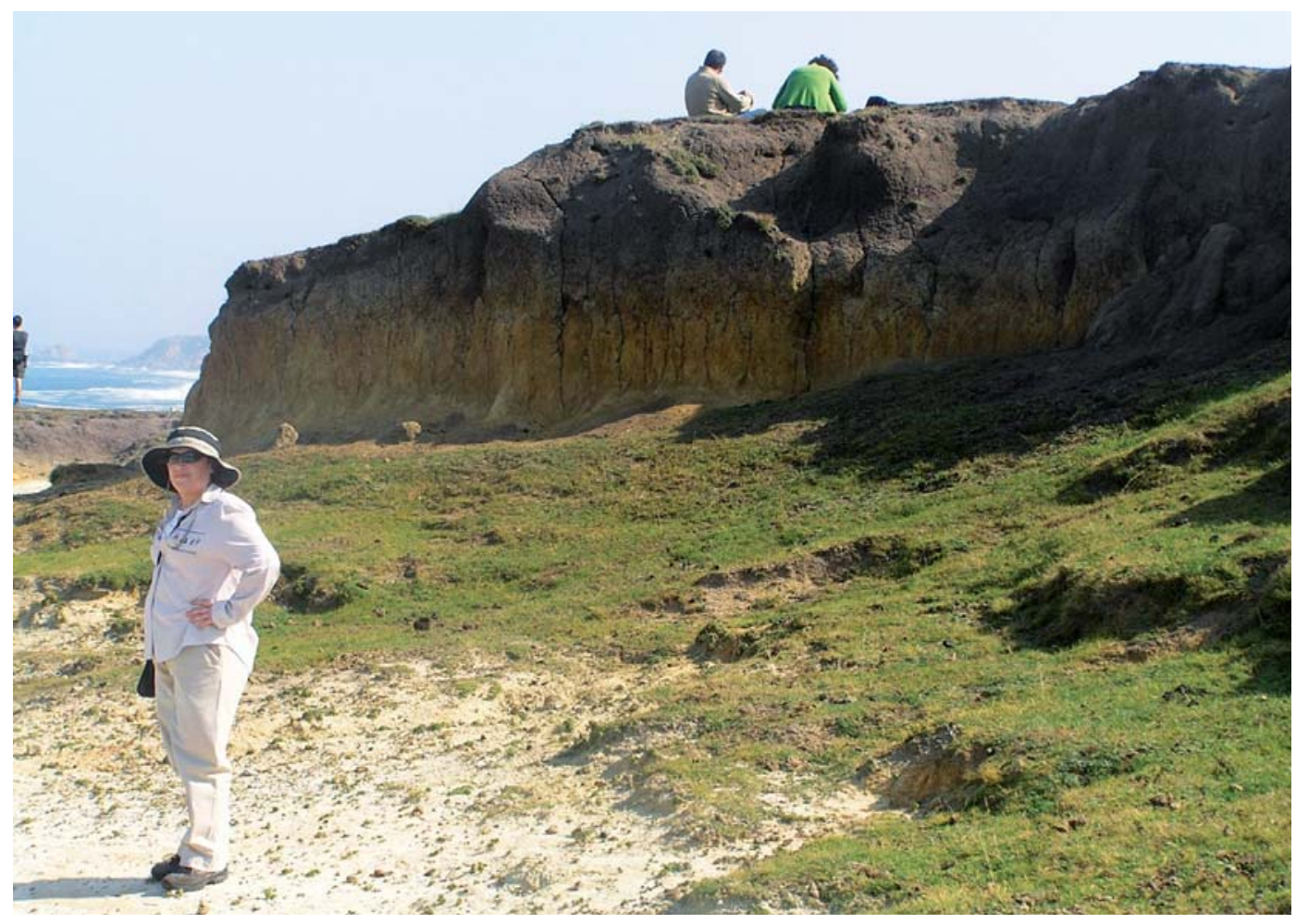

Fig. 10. - Corte estratigráfico del depósito de Marla.

10. Irudia. Marla metaketako ebaketa estratigrafikoa. 


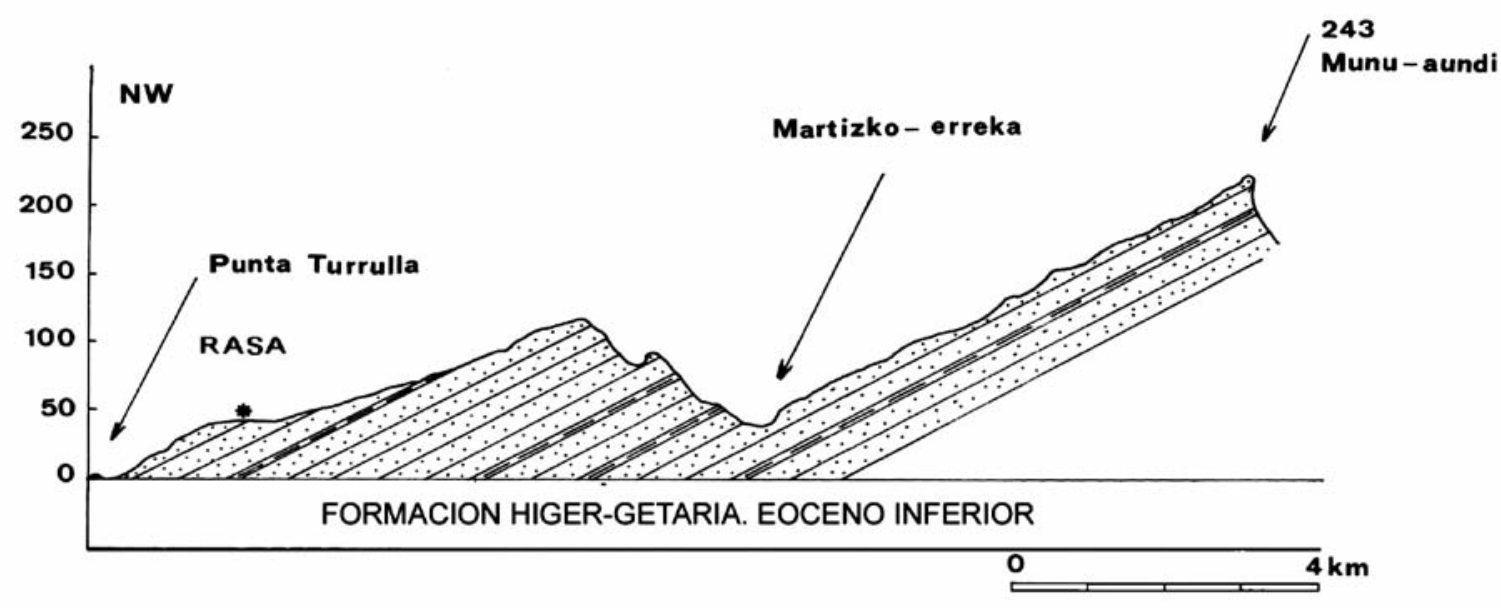

MONOCLINAL DEL JAIZKIBEL

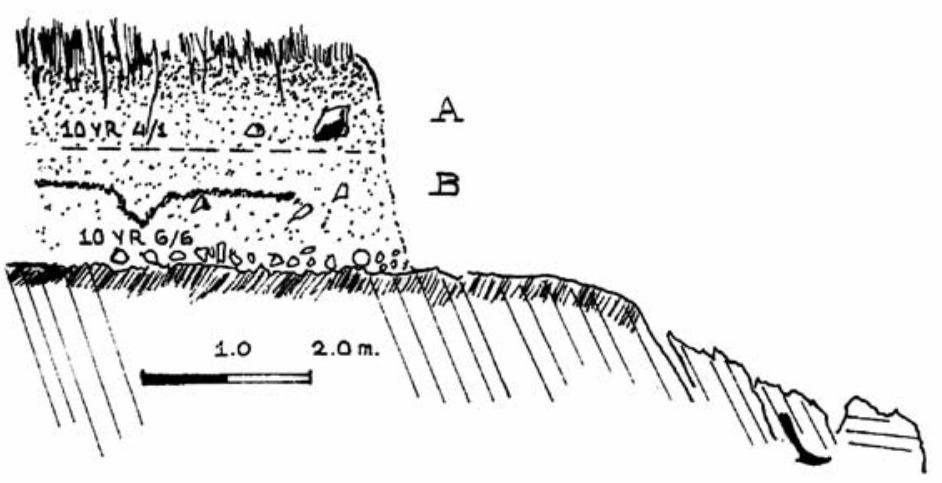

\section{DEPOSITO DE MARLA}

Fig. 11. - Perfil topográfico de Punta Turrulla y corte estratigráfico del depósito de Marla (Edeso \& Ugarte, 1990).

11. Irudia. Turrulla Puntako profil topografikoa eta Marlako metaketako ebaketa estratigrafikoa (Edeso \& Ugarte, 1990).

C.- Sobre un sustrato rocoso fuertemente alterado (arenizado como consecuencia de la disolución del carbonato cálcico) se dispone una delgada película de gravas, cantos rodados (Fig. 11 y 12) y, en algunos casos, fragmentos de óxidos e hidróxidos de hierro, empastados en una matriz arenosa pardo-amarillenta y/o blanquecina, cuyo origen se relaciona con los productos de alteración de la roca madre y con el sedimento depositado encima. En el sustrato pueden observarse diversas geoformas (gnammas, vaciados de "cannon balls" y pozas de evorsión turbillonar) recubiertas por películas de hierro.

B.- Nivel areno-limoso de 130/140 cm de espesor. Eventualmente se observan algunos fragmentos gruesos de areniscas angulosas, así como acumulaciones de óxidos de hierro de potencia irregular (entre 1 y $8 \mathrm{~cm}$ ) que dibujan festoneados y láminas alargadas. En su interior se han recogido diversos restos de talla, así como algo más de un centenar de útiles prehistóricos, entre los que casi un tercio corresponden a buriles, otros tantos a raederas y raspadores, unos pocos dorsos etc. lo que permite situar su cronología en el Magdaleniense (Merino, 1986).

A.- Suelo areno-limoso con abundante materia orgánica. Su espesor oscila entre los 50 y $60 \mathrm{~cm}$. Su composición es similar a la del nivel infrayacente, aunque disminuye el porcentaje de arenas a favor de los limos y de las arcillas.

La fracción gruesa que integra el nivel basal se caracteriza por su acusada heterogeneidad litológica. Predominan los cuarzos (51\%), seguidos de las areniscas (22\%), sílex (14\%), cuarcitas (7\%) y otras litologías (ofitas, doleritas...). Junto a estos materiales (Fig. 12 y 13) se observa (en algunos enclaves) una enorme cantidad de pequeños $(1-2 \mathrm{~cm}$ ) fragmentos de óxidos, oxihidróxidos e hidróxidos de hierro, cuyo origen parece relacionarse con procesos edáficos (alios) y con la destrucción de películas ferruginosas que se disponen rellenando diaclasas y planos de estratificación. 


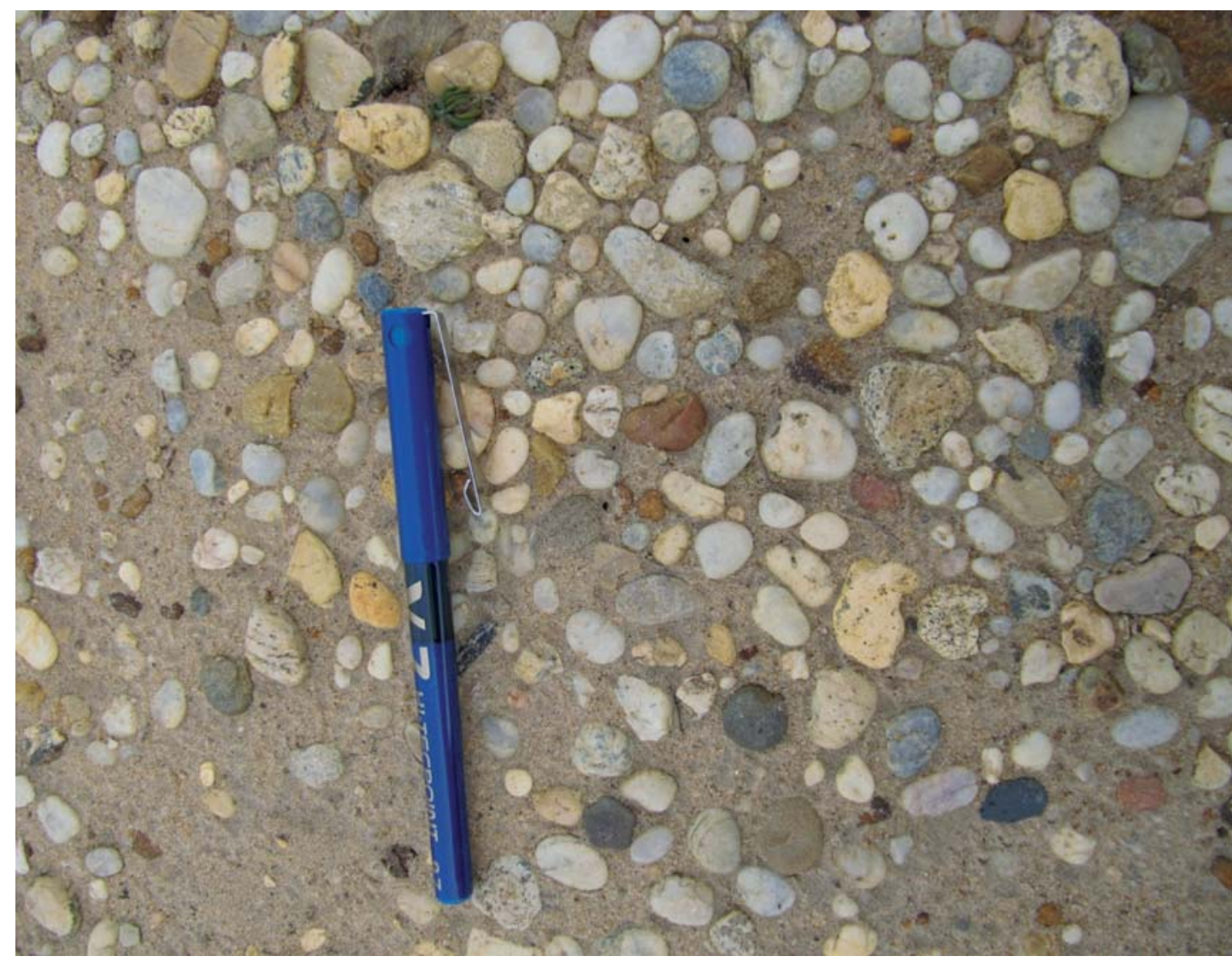

Fig. 12. - Nive pelicular de cantos y gravas que se disponen sobre la plataforma de abrasión

12. Irudia. Urradura-plataformaren gainean ezartzen den uharri eta legar geruza.

Desde un punto de vista granulométrico, los histogramas son unimodales con un máximo muy acusado en el intervalo comprendido entre 2 y $4 \mathrm{~cm}$ (Fig. 13). Los cantos pequeños $(2-6 \mathrm{~cm})$ son los más abundantes ya que suponen entre un 91 y un $96 \%$ del total analizado. El tamaño del material disminuye de $\mathrm{E}$ a $\mathrm{O}$, ya que el valor de la mediana de grano pasa de 3,7 cm en Marla, a 3,4 en Biosnar y a 3,3 cm en Punta Turrulla. El centilo experimenta una evolución similar, pasando de $10,3 \mathrm{~cm}$ a 8,7 $\mathrm{cm}$., respectivamente.

Todos estos materiales (excepto los fragmentos de hierro) están rodados, lo que pone de manifiesto que han sido movilizados en el seno de una corriente acuosa muy enérgica. Los índices de rodamiento varían en función de la litología y de la localización de la acumulación. Así, los cuarzos y las cuarcitas presentan valores que oscilan entre 187 y 246, mientras que los sílex fluctúan entre 238 y 254 (Edeso, 1990; 2005; Edeso \& Ugarte, 1990) y las areniscas se sitúan entre 251 y 344 (Fig. 13). En la mayor parte de los casos, los máximos del histograma (bimodales) se localizan en el intervalo 200-249, aunque tanto los cantos rotos $(<100)$ como los muy rodados $(>500)$ están bien representados.

Sobre estas gravas y cantos basales se desarrolla un nivel limo-arenoso de 190/200 cm de potencia. Dicho nivel se ha analizado a partir de los cortes de Marla $(160 \mathrm{~cm})$ y Txugur $(200 \mathrm{~cm})$ constatándose algunas diferencias entre ambas acumulaciones. En el corte de Marla la fracción are- nosa disminuye de muro a techo (pasa del 63,3 al 55,8\%) predominando, en la base, las arenas medias y en la parte alta las arenas finas, mientras que las gruesas son casi inexistentes. Todo ello se refleja en la media que pasa de 210 a $189 \mu \mathrm{m}$. El resto de los parámetros son bastante homogéneos: la clasificación y la selección son moderadas $(0,76 / 0,85)$, la asimetría es positiva y la angulosidad gráfica mesocúrtica. Los histogramas granulométricos son bimodales y las curvas hiperbólicas de tipo sigmoidal ligeramente tendidas, lo que pone de manifiesto que estamos ante un sedimento relativamente evolucionado cuya deposición fue semiforzada (¿brusca ruptura de pendiente?) no predominando ni el lavado ni la decantación. Estas características coinciden con las que presentan diversas acumulaciones coluviales existentes tanto en el frente como en el dorso del monoclinal (Edeso \& Ugarte, 1990).

En el corte de Txugur el tamaño de grano es menor que el observado en Marla, aunque dentro del perfil analizado se aprecia un ligero incremento de muro a techo. Predominan las arenas finas (entre un 67,1 y un $73 \%$ ) lo que se refleja en la talla media que oscila entre 177,3 y 189,7 um. La clasificación es moderada $(0,85 / 0,94)$, aunque algo peor que en Marla, la skewness simétrica y la angulosidad gráfica mesocúrtica. Los histogramas son bimodales y las curvas acumulativas transicionales entre las hiperbólicas y las sigmoidales (Fig. 14), lo que nos sugiere que la decantación ha predominado sobre el lavado y la deposición ha sido semiforzada. 
DEPOSITOS DE LA RASA DEL JAIZKIBEL $(\cdot 35-40)$
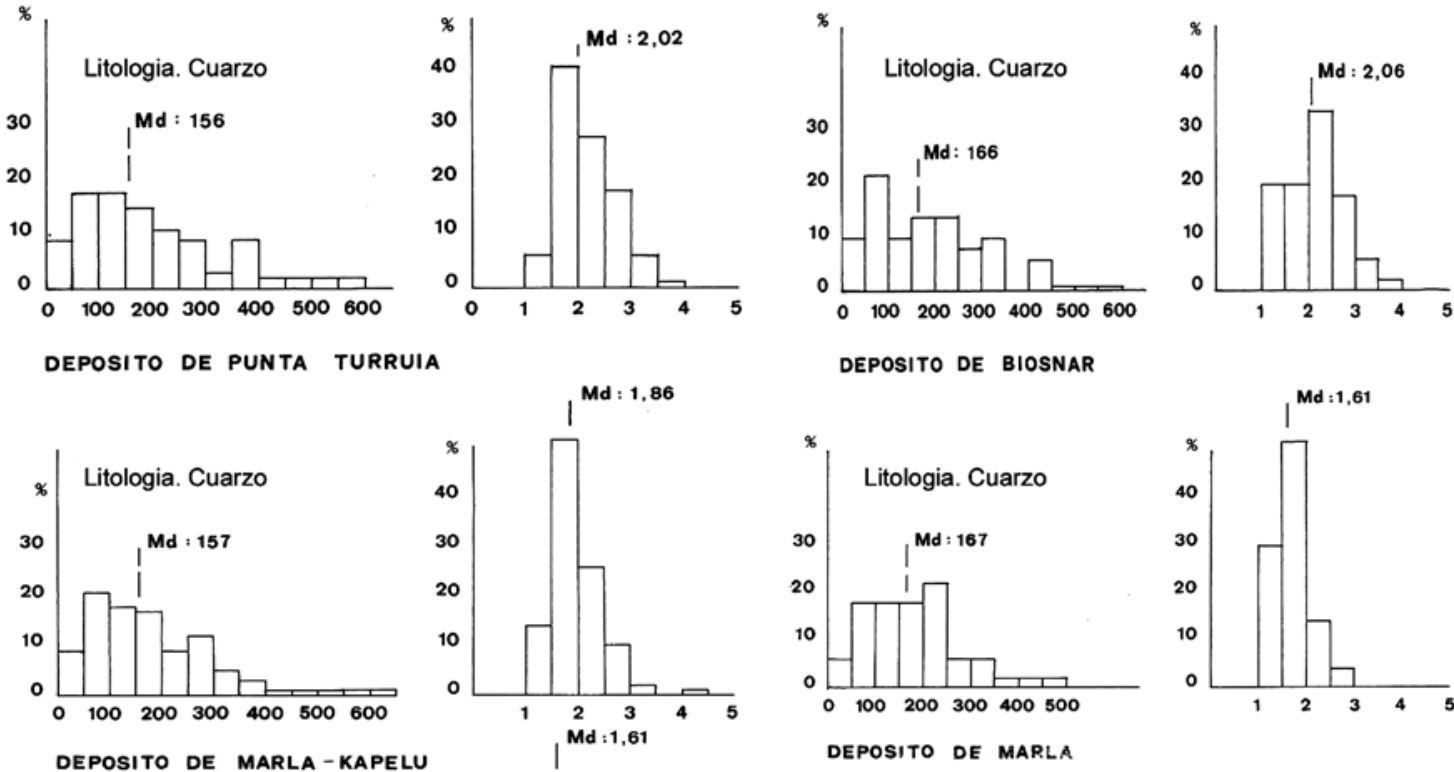

DEPOSITO DE BIOSNAR
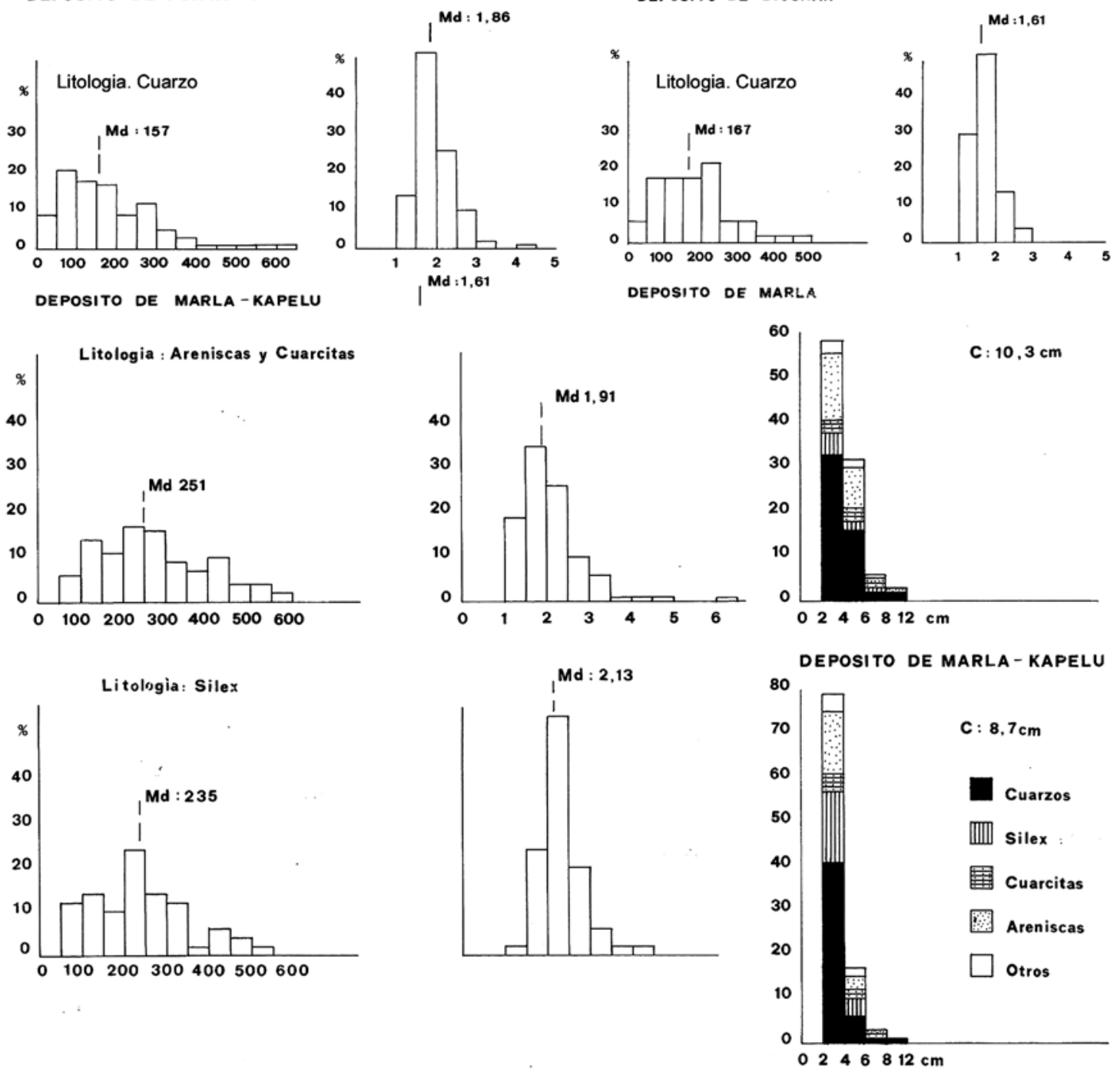

DEPOSITO DE PUNTA TURRUIA

Fig. 13. - Caracterización granulométrica y morfométrica de los materiales que integran el nivel basal de la plataforma de abrasión (Edeso, 1994). 13. Irudia. Urradura-lauguneko oinarriko maila eratzen duten materialen ezaugarritze granulometrikoa eta morfometrikoa (Edeso, 1994).

A la hora de interpretar estos valores hay que ser prudente, ya que estos parámetros granulométricos están fuertemente condicionados por los que presentan las rocas que integran el sustrato rocoso, lo que signi- fica que una parte de las características granulométricas puede ser heredada, apuntando hacia ambientes sedimentarios totalmente diferentes de los que originaron estas acumulaciones. 


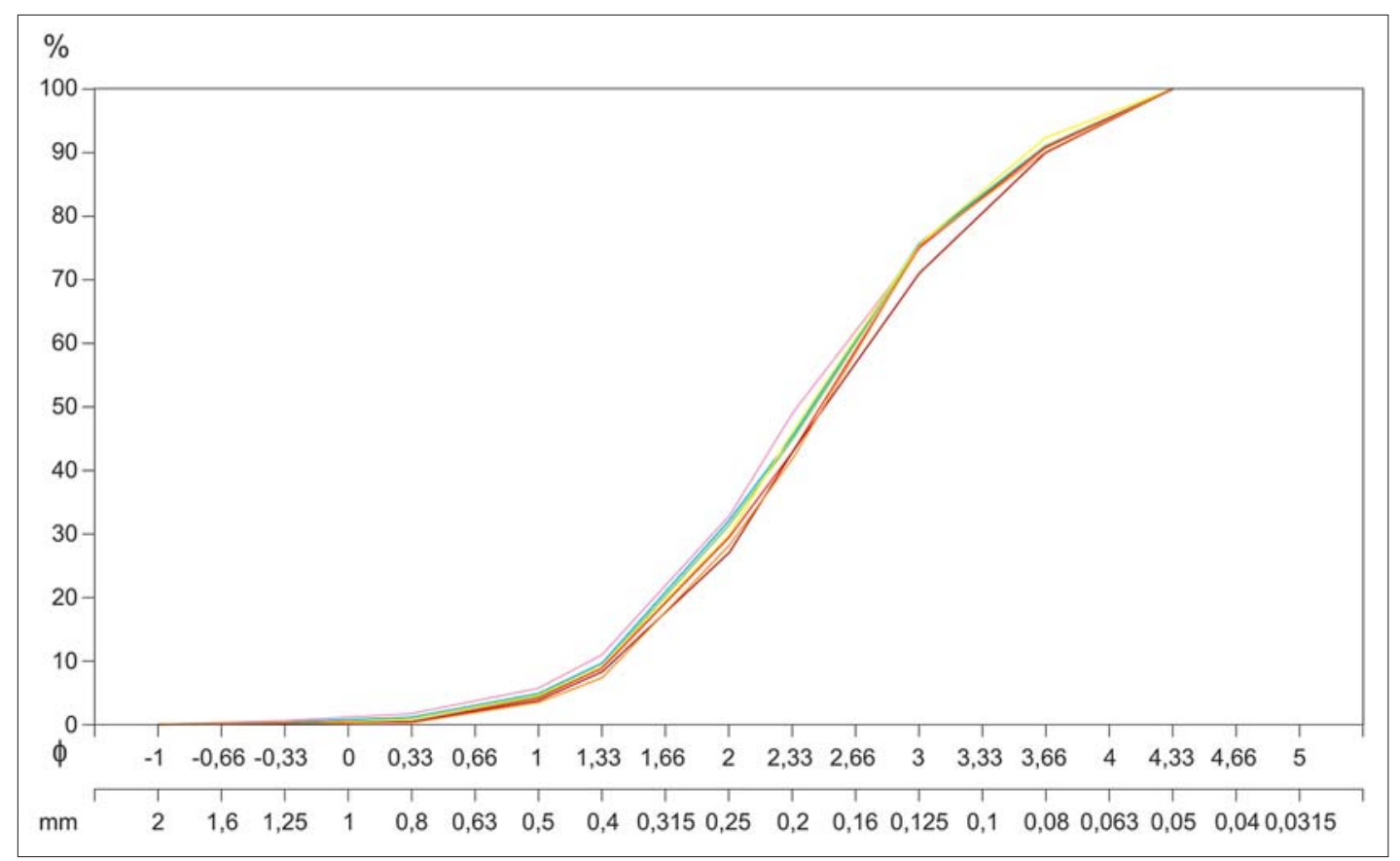

Fig. 14. - Curvas acumulativas (corte de Txugur). 14. Irudia. Metatze kurbak (Txugur-ebaketa).

\section{Origen y cronología de los niveles de rasa}

A pesar de la acusada fragmentación que presenta el nivel superior de rasa, existen suficientes evidencias que ponen de manifiesto el desarrollo de una plataforma de abrasión marina que biselaba las areniscas silíceas de la formación Higer-Getaria. Poco podemos decir respecto a su cronología, aunque formas similares localizadas en otros ámbitos geomorfológicos (Cantabria y Asturias), han sido atribuidas al Aquitano-Langhiense (Mioceno) por Mary (1992), mientras que otros autores le asignan una edad Pliocena y finipliocena (Moñino et al., 1987; González et al., 2005). En cualquier caso, tampoco en esos enclaves existen criterios de datación absoluta, por lo que la asignación de una u otra cronología es bastante especulativa.

El segundo nivel, mucho más continuo y mejor conservado, se desarrolla entre los 30 y 40 m por encima del 0 actual. Sobre la forma erosiva se extiende una película de sedimentos gruesos cuyo origen es alóctono, ya que los materiales que integran este nivel no afloran en el monoclinal (tampoco están presentes en las acumulaciones marinas actuales que salpican la costa de Gipuzkoa) y tampoco pueden haber sido arrastrados por los cursos cataclinales que drenan el dorso del monoclinal, ya que dichos cursos inscriben su cuenca dentro de la alineación Jaizkibel, no recibiendo ningún tipo de aporte procedente del exterior de la zona de estudio. Estos cursos sólo movilizan areniscas, lutitas y margas, por lo que el origen de los cantos y gravas debe ser exógeno. El análisis de los materiales depositados por los ríos Bidasoa, Oiartzun y Urumea (Edeso, 1990), nos permite descartar cualquier vinculación con los depósitos fluviales dejados por estos ríos, ya que tanto en las terrazas como en el relleno de fondo de valle no encontramos sílex, al mismo tiempo que el granito es muy abundante, litología que no aparece en las rasas de Jaizkibel.

Todas estas consideraciones nos inducen a pensar que tal vez estos materiales están relacionados con antiguos depósitos acumulados en la actual plataforma continental, habiendo sido posteriormente removilizados (pulsación transgresiva) por las olas y corrientes marinas hasta depositarse en su ubicación actual. Nada sabemos sobre el retroceso experimentado por la línea de costa durante el Pleistoceno y el Holoceno, ni sobre la evolución tectónica del espacio investigado, por lo que no podemos determinar la altura alcanzada por el nivel del mar durante la deposición, ni las variaciones experimentadas por el margen continental. La ausencia de elementos susceptibles de ser datados nos impide fijar una cronología exacta de la acumulación. Sin embargo, teniendo en cuenta su posición altimétrica (se sitúa por encima del depósito Eemiense de Anzaran) podemos especular que su cronología debe situarse en algún momento del Pleistoceno medio o inferior. Los niveles situados a +25-35 y +40-60 m en Cantabria, se atribuyen al Eemiense el primero (OIS-5) y al Holsteiniense (OIS-7) el segundo (González et al., 2005), aunque tampoco allí existen criterios de datación absoluta.

Dada su elevada posición altimétrica (+220-250 y +30-40 m) resulta difícil explicar su génesis atendiendo a criterios exclusivamente glacioeustáticos, siendo más lógico atribuir su origen a una combinación de movimientos epirogenéticos, isostásicos y glacioeustáticos (Mary, 1979, 1992; Flor, 1983). La presencia de materiales alóctonos sobre la plataforma inferior, pone de manifiesto que su deposición se produjo durante una fase transgresiva (o de estancamiento del nivel del mar tras la elevación) que, en otros ámbitos, diversos autores (González et al., 2005; Flor, 
1983; Mary, 1992) vinculan al interglaciar Holsteiniense con un nivel marino entre 15 y 20 metros por encima del actual o incluso al Cromeriense, momento en el que el mar se situaba $23 \mathrm{~m}$ por encima de su posición actual.

El nivel areno-limoso que recubre la rasa presenta una cronología mucho más reciente. La presencia de diversos útiles prehistóricos en su interior, sitúan esta acumulación (Merino, 1986) entre el Magdaleniense Final y el Tardiglaciar (16000-12000 BP). Los diversos rasgos sedimentológicos observados, junto con la información obtenida en algunos depósitos en fase de investigación, pone de manifiesto que su transporte y posterior deposición se vincula con procesos de arroyada laminar en condiciones rexistásicas y bajo un clima frío y húmedo (Edeso, 1990, 1994, 2005; Bertrand et al., 2009). Desgraciadamente, los análisis palinológicos efectuados han resultado estériles.

\section{El depósito de Goizut}

Se localiza dentro del casco urbano de Hondarribia (edificios Iterlimen), a unos 35 metros de altitud sobre un paleoacantilado (Fig. 15) que se dispone dominando la playa de Hondarribia, en el frente del monoclinal de Jaizkibel. El depósito se apoya sobre los materiales que integran el flysch guipuzcoano (alternancia de niveles turbidíticos con otros de precipitación química) cuya edad es Paleoceno medio y Eoceno inferior (Campos, 1979). Desconocemos sus dimensiones exactas, pero sabemos que al menos tiene $90 \mathrm{~m}$ de largo por 50 de ancho, aunque ha sido parcialmente destruido en los últimos años, como consecuencia de la fuerte expansión urbanística de Hondarribia.

Sobre estos materiales, y con un contacto claramente erosivo (¿paleocanal?), se disponen 8 metros de sedimento (Edeso y Ugarte, 1990; Edeso, 1990; 1992), presentando la siguiente secuencia estratigráfica (Fig. 16): (1) nivel basal, (2) nivel arenoso de color pardo-amarillento, (3) nivel de gravas y cantos, (4) nivel arenoso superior, y (5) suelo subactual.
El nivel basal (7.5YR 5/6) (Muestras A1 y A2) tiene una potencia máxima observable de 3,5 m. Está constituido por bloques, cantos y gravas de litología diversa empastados por una matriz areno-limosa muy abundante. Se definen como gravas masivas o algo estratificadas, presentando estratificación horizontal e imbricación de los materiales (código de facies Gm) (Miall, 1977). Se observa también una disminución del tamaño de grano de muro a techo, mientras que el índice de redondez no experimenta cambios significativos, oscilando su valor entre 260/287 (se ha utilizado como litología guía el cuarzo).

En la base del nivel la fracción gruesa representa el $68 \%$ del total analizado, predominando los cantos pequeños $(74 \%)$, mientras que los bloques tan sólo suponen el $1 \%$. Todo ello se refleja en la talla media del sedimento que apenas alcanza los 4,7 cm., mientras que el centilo se eleva hasta los $44 \mathrm{~cm}$. Litológicamente predominan las areniscas (45\%), seguidas por el cuarzo (17\%), las cuarcitas (14\%) y los esquistos (19\%). El resto de materiales representan un 5\% y están integrados por conglomerados y margocalizas, así como por algunos clastos que no han podido ser identificados debido a su considerable alteración.

En el techo del nivel la fracción gruesa disminuye oscilando entre el 34 y el $56 \%$ del total analizado. Predominan las gravas y los cantos pequeños (89\%), lo que sitúa la talla media en torno a los $3,8 \mathrm{~cm}$. Si bien la composición litológica permanece invariable de muro a techo, los porcentajes de cada una de las litologías experimentan cambios importantes. Los cuarzos lechosos aumentan considerablemente, pasando del 17 al 39\%, mientras que las areniscas disminuyen representando "tan sólo" el 35\%. Lo mismo podemos decir de las cuarcitas (13\%), los esquistos (6\%) y del resto de litologías. Todas ellas están muy alteradas, -excepto los cuarzos y las cuarcitas- por lo que los materiales menos resistentes se han descompuesto casi totalmente. Los subproductos originados por dicha descomposición pueden haber modificado los parámetros sedimentológicos de la fracción fina.

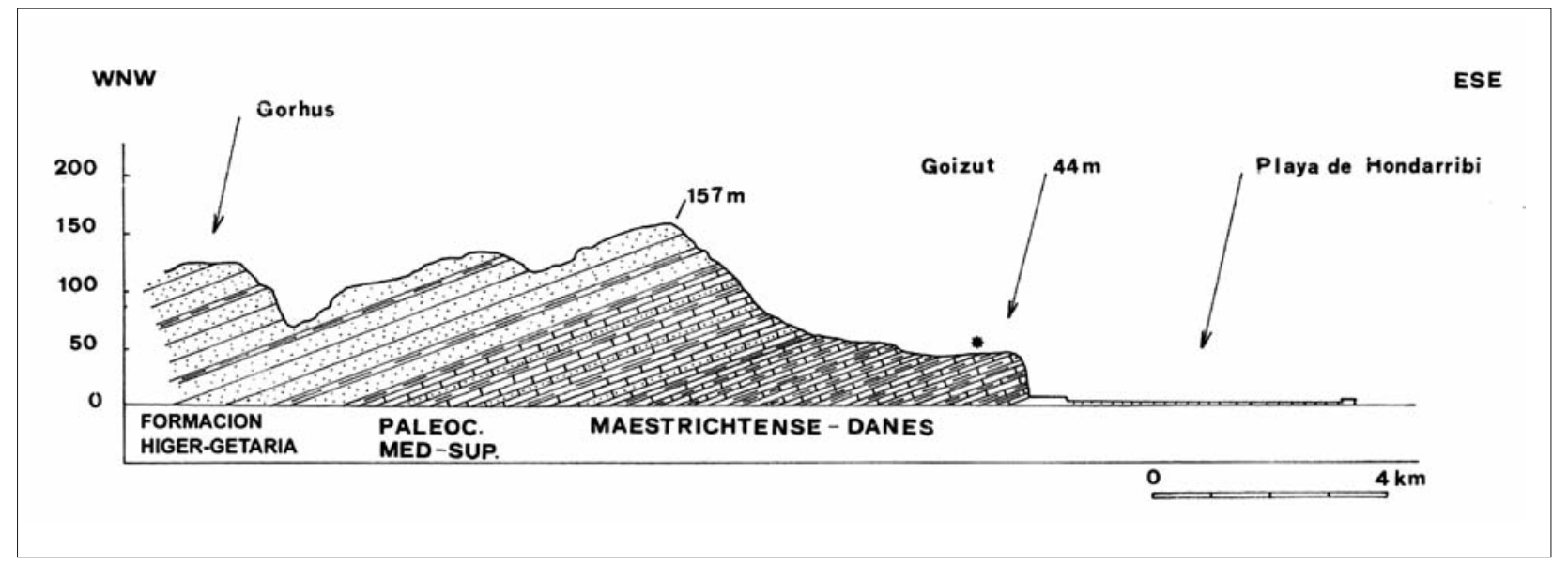

Fig. 15. - Perfil topográfico del sector de Goizut (Edeso, 1993)

15. Irudia. Goizut inguruko profil topografikoa (Edeso, 1993). 


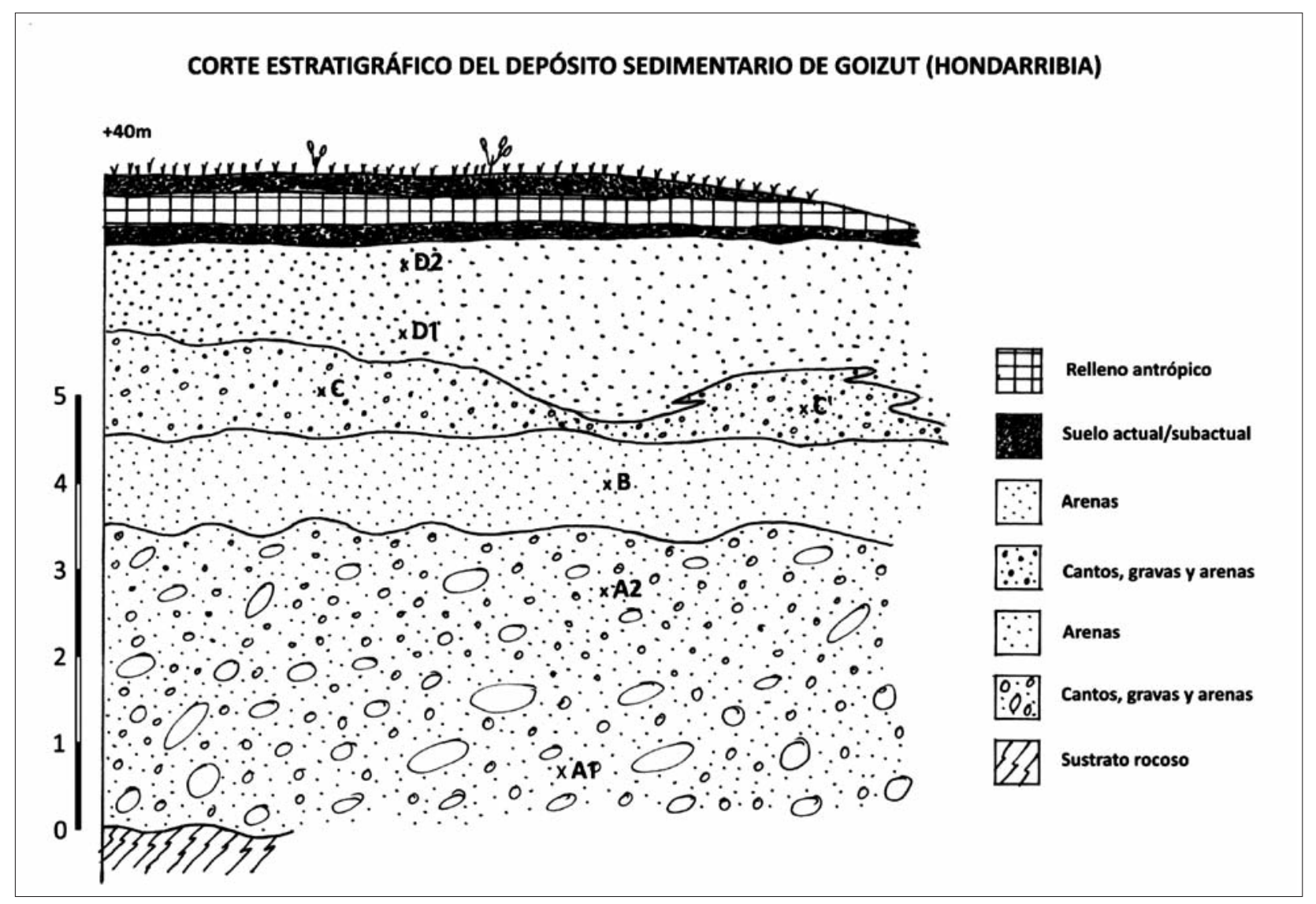

Fig. 16. - Reconstrucción esquemática del depósito de Goizut.

16. Irudia. Goizut metaketako berreraikiketa eskematikoa

Morfométricamente el índice de rodamiento varía según la litología considerada (Cailleux \& Tricart, 1963). Los cantos de cuarzo presentan valores en torno a 246, mientras que en el caso de las areniscas este valor se eleva hasta 344. Tanto los cantos rotos $(<100)$ como los muy rodados (> 500) representan el $7 \%$ del total (el 2 y el $27 \%$ en el caso de las areniscas). Valores similares se observan en las terrazas fluviales de los ríos Bidasoa, Oiartzun y Jaizubia (Edeso, 1990, 2007).

La fracción fina es areno-limosa. En la base las arenas representan el $73 \%$ del total analizado, mientras que en el techo del nivel esta cifra no rebasa el 65,6\%. Predominan las arenas de talla gruesa $(41,3$ y $34,2 \%$ respectivamente) y, en menor grado, las medias (21,2 y $18,7 \%$ ). Todo ello se refleja en la media que pasa de 517 $\mu \mathrm{m}$ en la base a $467 \mu \mathrm{m}$ en el techo del nivel. El resto de parámetros granulométricos no presentan diferencias significativas (Fig. 17): histogramas polimodales con retenciones importantes en varios intervalos granulométricos, curvas parabólicas, mala selección y clasificación ( $\sigma$ i: $1,21 / 1,32)$, asimetría positiva y angulosidad gráfica platicúrtica/mesocúrtica. Todo ello nos indica que estamos ante un sedimento heterométrico, poco evolucionado, cuya deposición ha sido forzada predominando la decantación sobre el lavado. Rasgos similares presentan las terrazas y las acumulaciones fluviales Pleistocenas y
Holocenas de los ríos guipuzcoanos situados en el entorno de Cinco Villas (Edeso, 1990, 2007).

En cuanto al nivel arenoso de color pardo-amarillento (10YR 6/8), con estratificación laminar y sin fracción gruesa (Muestra B), su potencia oscila en torno a los 100 $\mathrm{cm}$. La fracción arenosa supone el 88,6\% del total analizado, predominando las arenas medias $(56,4 \%)$ y finas (24\%), de ahí que la talla media se sitúe en $246 \mu \mathrm{m}$. El histograma granulométrico es unimodal, la curva acumulativa sigmoidal ligeramente tendida, la clasificación moderada/buena, la asimetría negativa y la angulosidad gráfica leptocúrtica (Corrales et al., 1977). Estamos ante un sedimento homométrico, bien evolucionado, cuya deposición fue ligeramente forzada, predominando la decantación sobre el lavado.

Nivel de gravas y cantos (Muestras C y C'). El contacto con el nivel arenoso subyacente es claramente erosivo. En algunos puntos configura un manto continuo mientras que en otros adopta un dispositivo lenticular (¿relleno de canal?) muy nítido. Su espesor oscila entre los 50 y los $110 \mathrm{~cm}$, no observándose estructuras sedimentarias.

Es un sedimento heterométrico. La fracción gruesa supone el 8,8\% del total, presentando una composición y características texturales similares a las observadas en 


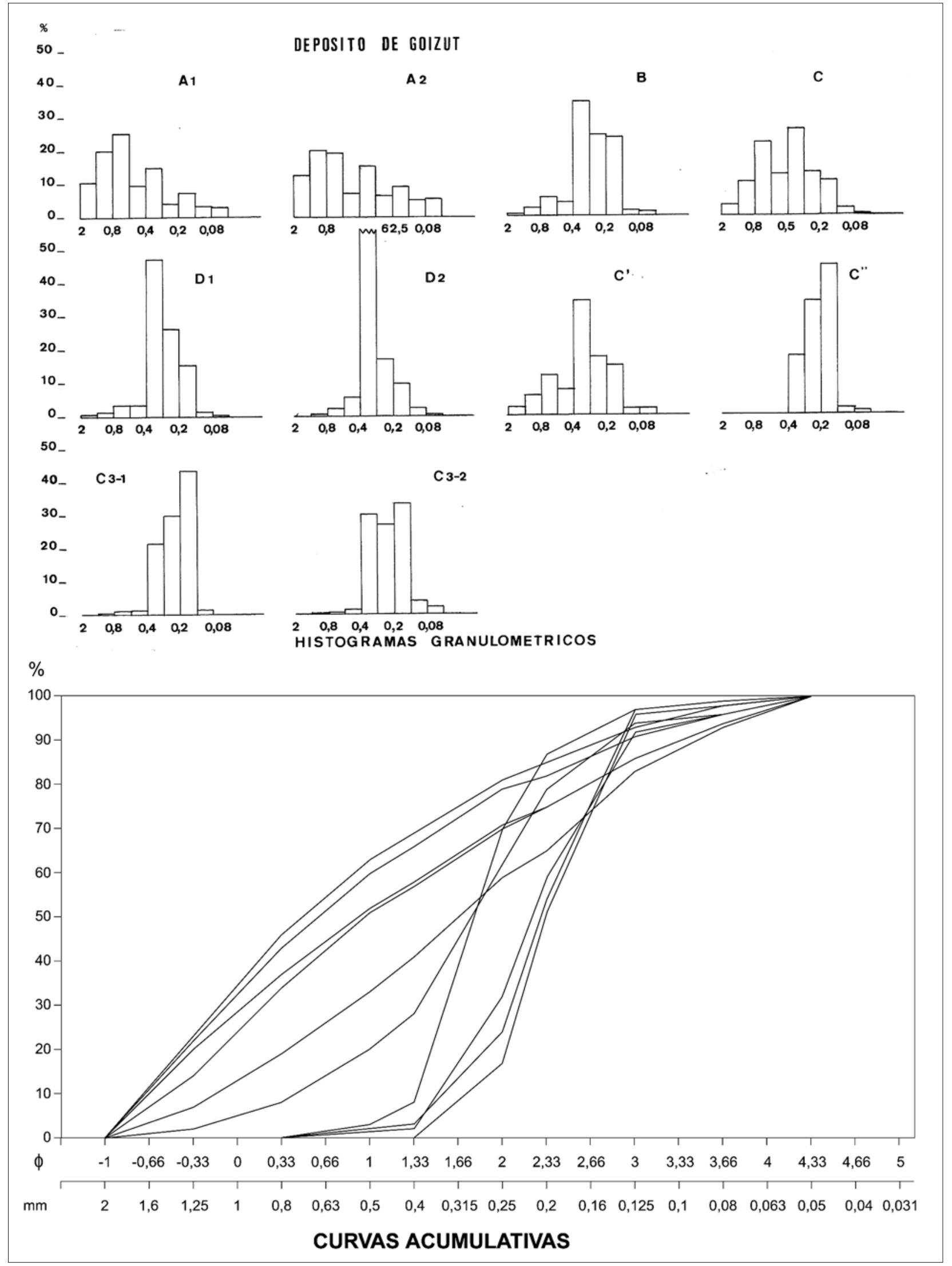

Fig. 17. - Histogramas granulométricos y curvas acumulativas del depósito de Goizut (Edeso, 1993)

17. Irudia. Goizut metaketako histograma granulometrikoak eta metatze kurbak (Edeso, 1993). 
la base de la acumulación. La fracción arenosa oscila entre el 78 y el $83 \%$ del total de finos analizados, predominando las arenas de talla media $(40,8-50,1 \%)$ y en menor medida las gruesas (17,2-27,8\%), de ahí que la talla media oscile entre 296 y $375 \mu \mathrm{m}$. Los histogramas granulométricos son claramente bimodales (mezcla de dos subpoblaciones diferentes), las curvas acumulativas sigmoidales sumamente tendidas, la clasificación mala, la skewness simétrica y la angulosidad gráfica mesocúrtica. Es decir, estamos ante un sedimento poco evolucionado, cuya deposición se produjo en condiciones semiforzadas, no predominando ni el lavado ni la decantación.

Transversalmente (Muestra C"' y C3-1) los elementos gruesos desaparecen, haciéndose dominantes las arenas $(89,8 \%)$, predominando las arenas medias $(46,6 \%)$ y finas $(43,2 \%)$, al mismo tiempo que desaparecen las gruesas. El histograma granulométrico es unimodal y la curva acumulativa sigmoidal sumamente enderezada. La clasificación es buena, la skewness simétrica y la angulosidad gráfica mesocúrtica. Es un sedimento homométrico, bien evolucionado, cuya deposición ha sido libre por exceso de carga. Características similares se observan en las acumulaciones marinas y/o eólicas actuales (Edeso, 1990).

El nivel arenoso superior (Muestras D1 y D2) tiene un espesor medio de $100 \mathrm{~cm}$. Presenta estratificación cruzada de bajo ángulo, siendo el contacto con los materiales subyacentes claramente erosivo. La fracción gruesa supone el 1,9\% del total y está constituida por nódulos arenosos cementados por carbonatos.

La fracción fina es arenosa (86,8\%), predominando las arenas de talla media $(73,9 \%)$ lo que sitúa la media en $308 \mu \mathrm{m}$. Los histogramas son unimodales y las curvas sigmoidales enderezadas. La clasificación es buena, la skewness simétrica y la angulosidad gráfica mesocúrtica. Es decir estamos ante un sedimento homométrico, bien evolucionado y que ha experimentado un transporte completo. La deposición ha sido libre por exceso de carga predominando la decantación sobre el lavado. Características similares se observan en los depósitos eólicos actuales (Edeso, 1990; Edeso \& Ugarte, 1990).

Finalmente aparece el suelo subactual, de $15 \mathrm{~cm}$ de potencia, que está enterrado por escombros y restos de construcción.

Desde el punto de vista mineralógico, se han analizado 3 muestras recogidas en la parte alta, media y baja del depósito (López Azcona, inédito). Si bien en todos los casos el cuarzo es el mineral dominante, advertimos una mayor riqueza mineralógica en el muro de la acumulación, disminuyendo ésta a medida que ascendemos en el perfil. Así, en la base encontramos, además del ya citado cuarzo, cantidades significativas de moscovita y, en menor proporción, caolinita, yeso, illita, goetita y ortoclasa.

En el nivel intermedio, el cuarzo sigue siendo muy abundante y va acompañado de moscovita (bastante abundante), yeso, illita y goetita (escasos). Por último, en el tramo superior el empobrecimiento es aún más acu- sado, ya que además del cuarzo sólo encontramos moscovita e indicios de yeso.

Estos resultados ponen de manifiesto que las características mineralógicas de las muestras analizadas son muy semejantes, con una evidente pérdida de minerales de muro a techo. Su similitud nos induce a pensar que e área de alimentación era similar en todos los casos.

El análisis de las diversas muestras (Cearreta et al., 1992) pone de manifiesto que todas ellas son estériles excepto las procedentes de la parte alta del perfil (niveles 3 y 4), donde se observa una asociación de foraminíferos bentónicos mal conservados, constituidos por individuos de los géneros Cibicides, Rosalina y Textularia.

Los análisis palinológicos efectuados por Peñalba (inédito) ponen de manifiesto que todas las muestras analizadas son estériles.

A tenor de la información disponible podemos afirmar que estamos ante un depósito complejo, situado en un emplazamiento que poco tiene que ver con el paisaje dominante en el momento de su formación. La similitud altimétrica de este depósito con las rasas anteriormente analizadas (y con las acumulaciones de Irubide y Manziategi, situadas en el valle ortoclinal Irún-San Sebastián) (Edeso, 1990; Cearreta et al., 1992; Edeso, 1994), nos induce a pensar que ambas acumulaciones se han originado de manera coetánea en el tiempo, teniendo por lo tanto una cronología muy similar. Sin embargo, la mayor complejidad del depósito de Goizut nos permite establecer diversos ambientes sedimentarios.

El nivel basal puede interpretarse como una barra de canal de origen fluvio-torrencial, depositada en condiciones sumamente enérgicas y en un medio claramente continental. El origen del sedimento está vinculado al entorno de Cinco Villas, pero la ausencia de granito nos indica que su deposición no se relaciona con el río Bidasoa, sino que debe vincularse a la actividad del río Jaizubia, cuyos depósitos presentan características composicionales similares a las observadas en Goizut. A medida que estos espacios son transgredidos por el mar, las condiciones hidrodinámicas iniciales se modifican, disminuyendo la competencia del agente, lo que se traduce en una modificación sustancial de las características del sedimento. Es posible que el medio continental evolucionase hacia una paleodesembocadura produciéndose una mezcla de aportes de origen diverso.

Paulatinamente, estos ambientes fluviales o fluvio-torrenciales son sustituidos por otros marinos, lo que determina la deposición de sedimentos arenosos bien clasificados (ambiente enérgico y selectivo). Es posible que sigamos estando en una paleodesembocadura (¿estuario?) pero con un claro predominio de la actividad marina. A medida que el nivel del mar se incrementa, esta paleodesembocadura evoluciona hacia ambientes francamente marinos, conformándose una playa (o una plataforma intermareal arenosa) surcada por canales fluvio-mareales de tamaño métrico (niveles lenticulares). El techo del depósito tiene ya un origen eólico, lo que nos 
sugiere que, o bien todo el conjunto sedimentario es progradante o se produjo una pulsación regresiva (o un levantamiento neotectónico) lo que permitió el desarrollo de cordones dunares.

Intentar establecer la cronología de esta acumulación es harto complicado ya que no tenemos evidencias susceptibles de ser datadas ${ }^{3}$ de una manera absoluta. Sin embargo, su posición por encima del depósito de Anzaran (Edeso, 1990; Cearreta et al., 1992; Edeso et al., 1993) que ha sido datado como Eemiense, nos permite determinar que su antigüedad es mayor, lo que se ve confirmado por el elevado grado de descomposición de los elementos que integran la acumulación. Teniendo en cuenta estas consideraciones, la edad de Goizut se situaría durante alguna de las fases transgresivas acaecidas durante el Pleistoceno Medio o Inferior (¿Holsteiniense?¿Cromeriense?).

\section{Depósitos y formas erosivas Holocenas recientes}

Estos depósitos y formas erosivas únicamente se han localizado en el sector oriental de Jaizkibel (las características morfo-lito-estructurales del sector occidental explican su ausencia) y, más concretamente, en el espacio desarrollado entre punta Turruia y Artzuko Portu. De Oeste a Este encontramos las siguientes evidencias:

\section{Artzuko Portu}

Es una profunda entalladura de dirección NE-SO que interrumpe bruscamente el acantilado actual. En su fondo se constatan diversas acumulaciones arenosas situadas, unas en el intermareal y otras por encima del máximo nivel alcanzado por la pleamar (Fig. 18). Estas últimas se localizan colmatando el tramo final de Erramudiko Erreka, pequeño curso fluvio-torrencial que presenta un brusco escalón (de unos 5-6 metros) doscientos cuarenta metros antes de alcanzar el nivel del mar. El relleno tiene una potencia máxima observable de 1,5 metros y está constituido, casi exclusivamente, por arenas (> 98\%). Los análisis granulométricos efectuados nos indican que predominan las arenas de talla media, de ahí que la media oscile entre las 225 y las $291 \mu \mathrm{m}$, mientras que en las acumulaciones marinas predominan las arenas gruesas, oscilando la media entre las 494 y las $638 \mu \mathrm{m}$.

Presentan histogramas granulométricos unimodales (bimodales las de origen fluvial) y curvas sigmoidales ligeramente tendidas (Fig. 19) (sedimentación forzada provocada por la brusca disminución de la pendiente). La selección y la clasificación son moderadas/buenas, la asimetría gráfica inclusiva simétrica y la angulosidad gráfica mesocúrtica. Aunque el origen del sedimento es fluvio-torrencial y sus parámetros granulométricos están fuertemente influenciados por los de la roca madre original, algunos rasgos de la acumulación, como por ejemplo la selección-clasificación y las curvas acumulativas, junto con la presencia de algunos fragmentos de concha (en fase de disolución), nos permiten afirmar que su deposición se ha producido en un ambiente marino (desembocadura) parcialmente restringido.

\section{Marla}

En el paraje denominado Marla (Aingiraputzu) se localiza una plataforma erosiva de 51,6 m de largo, $26 \mathrm{~m}$ de ancho y 1,8 m de profundidad máxima (Fig. 20). Está parcialmente inundada ya que en ella vierte sus aguas el pequeño curso cataclinal de Iturraingo erreka, así como algunos rezumes temporales existentes en el sector occidental. La plataforma interrumpe bruscamente el acantilado actual, situándose 1,5/2 m por encima del máximo nivel alcanzado por la pleamar. Justo por debajo de ella se está modelando una segunda plataforma (mucho más modesta) enlazando ambas mediante una rampa de fuerte pendiente $\left(25^{\circ}\right)$. Una rampa de características similares (aunque de mayor desarrollo) domina su borde interno, obligando al río Iturraingo a difuminarse en una amplia lámina acuosa con el fin de salvar los $8 \mathrm{~m}$ de desnivel existentes entre el valle y la plataforma.

En su parte interna se desarrolla un cordón de cantos y bloques constituido por areniscas silíceas y calizas arenosas. Este cordón tiene una longitud aproximada de $40 \mathrm{~m}$ oscilando su anchura entre los 0,5 y los 2,1 m mientras que

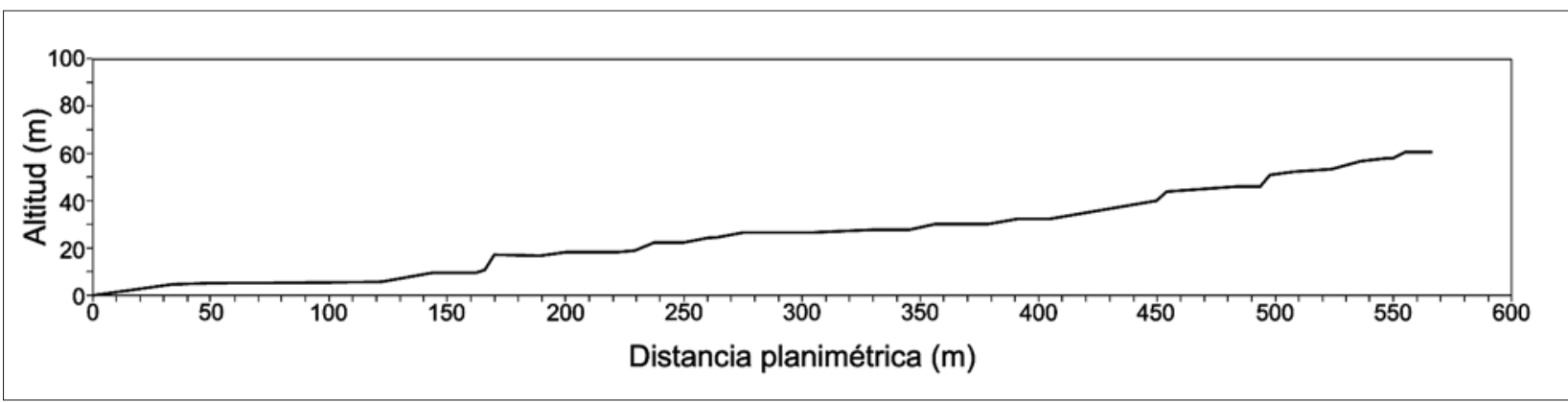

Fig. 18. - Perfil longitudinal de Erramudiko erreka. Advertimos el amplio rellano que se desarrolla justo por encima de la desembocadura. 18. Irudia. Erramudiko errekako luzetarako profila. Jakinarazten dugu bokalaren gainean zuzenean garatzen den laugune zabala.

\footnotetext{
${ }^{3}$ La intensa edificación urbanística acaecida durante las últimas décadas impide la obtención de muestras susceptibles de ser datadas mediante las nuevas tecnologías desarrolladas en épocas recientes.
} 


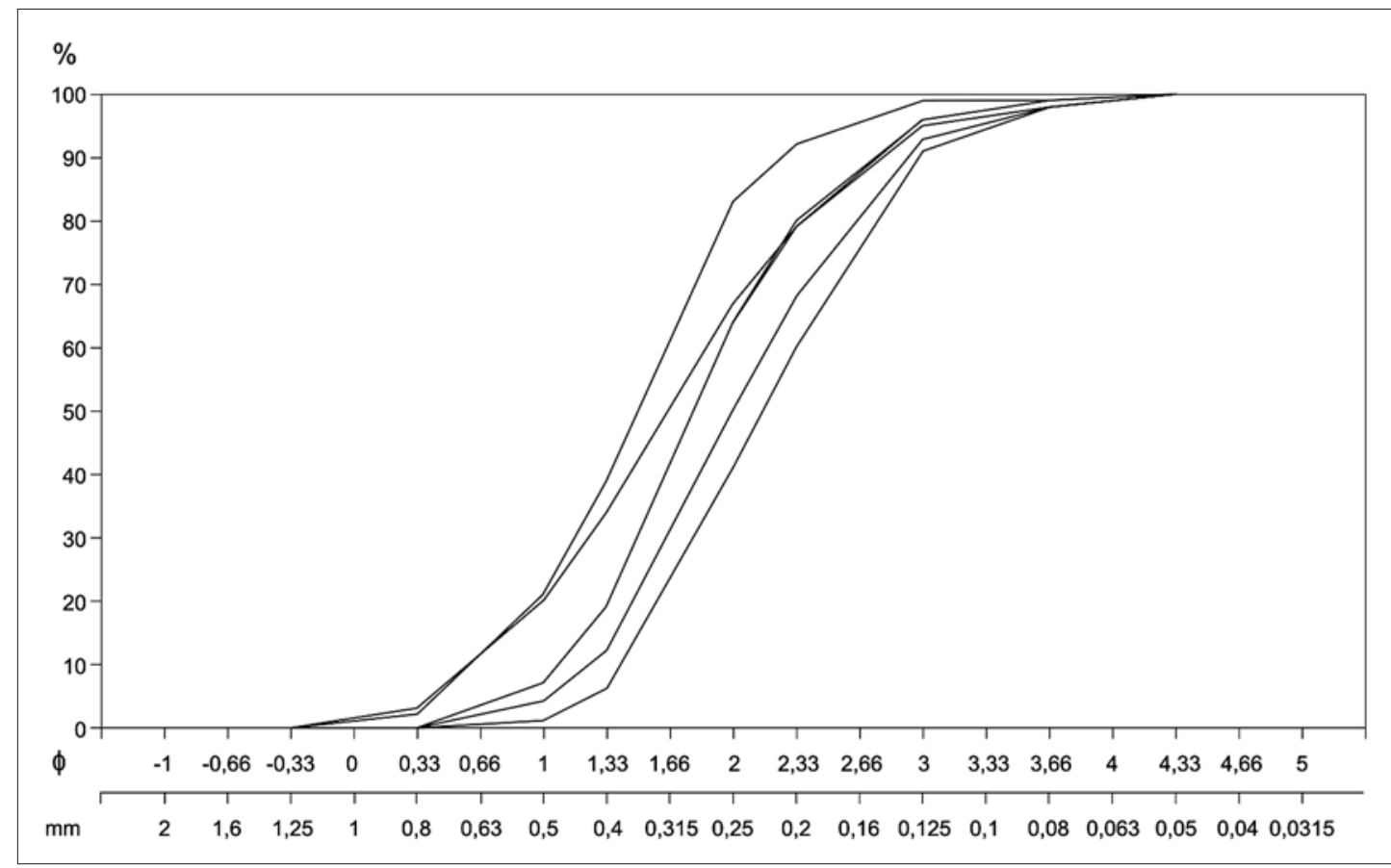

Fig. 19. - Curvas acumulativas de relleno arenoso de Artzuko Portu.

19. Irudia. Artzu Portuko betelan hondartsuaren

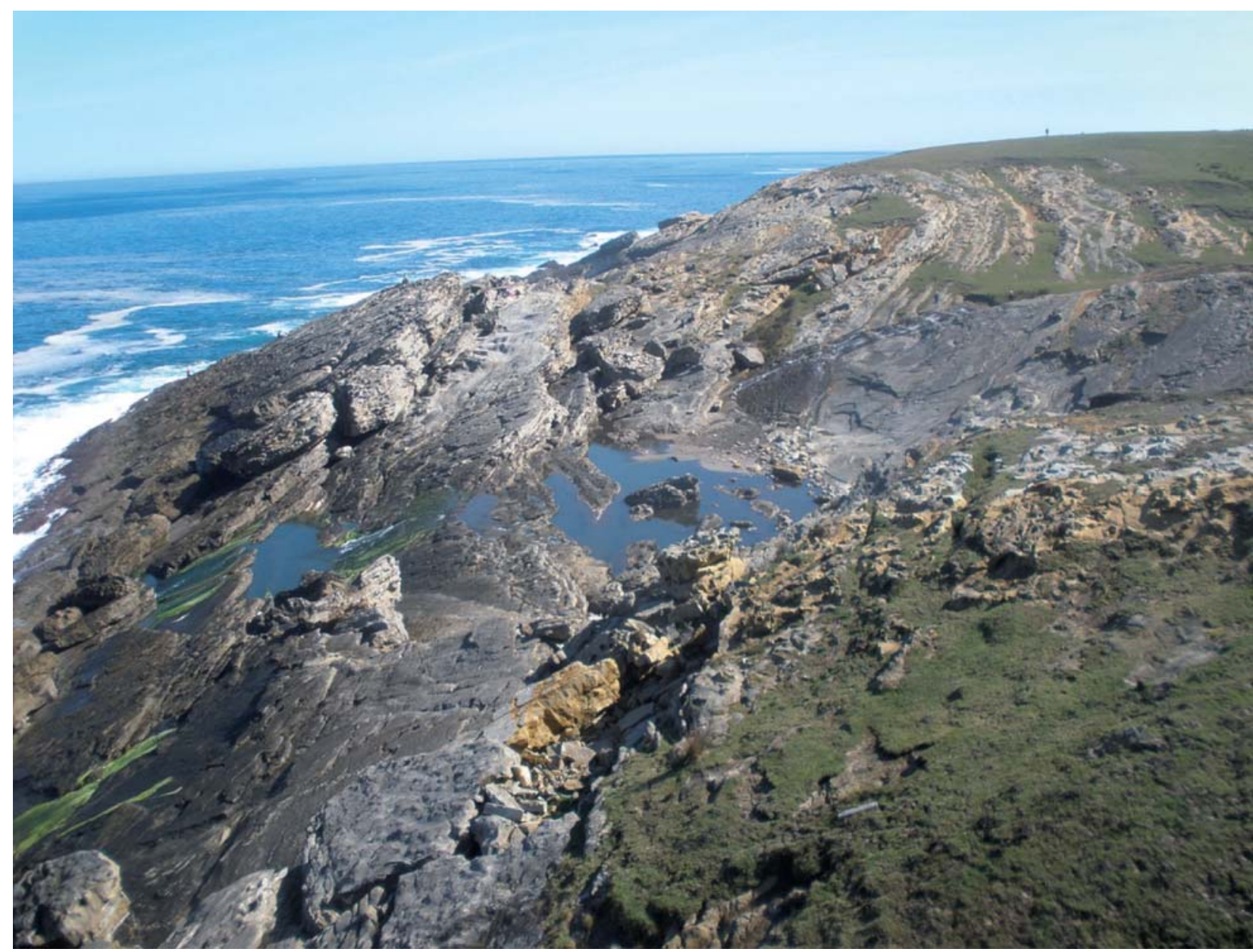

Fig. 20. - Vista general de la plataforma erosiva de Marla. 20. Irudia. Marlako higadura plataformaren ikuspegi orokorra. 
su espesor no supera los 0,5 m. Existen algunas diferencias granulométricas entre el sector oriental y el occidental. Así, en la zona oriental (afectada por los aportes del curso citado anteriormente) predominan los cantos pequeños (2-6 $\mathrm{cm}$ ) superando éstos el $71 \%$ del total analizado. No se observan bloques lo que sitúa la mediana de grano en torno a $4,1 \mathrm{~cm}$ y el centilo en $15,5 \mathrm{~cm}$. Morfométricamente los valores obtenidos son similares a los que presentan las acumulaciones marinas actuales (Ugarte \& Edeso, 1987; Edeso \& Ugarte, 1990; Edeso, 1990; 1994, 2005), con un índice de rodamiento que oscila entre 255 y 270 (el de aplanamiento varía entre 1,97 y 2,14 ). Estos valores tan discretos son consecuencia directa del elevado porcentaje de cantos (rodados) rotos (20\%) lo que pone de manifiesto la alta energía del medio, capaz de fragmentar los cantos a pesar de su considerable dureza.

El sector occidental está dominado por un escarpe vertical inestable de $10 \mathrm{~m}$ de altura, lo que explica la presencia de grandes bloques (algunos de tamaño métrico) angulosos de arenisca y caliza arenosa alterada. Este escarpe (¿paleoacantilado?) está sometido a intensos procesos subaéreos por lo que ocasionalmente se producen caídas de bloques y pequeños desprendimientos. Al margen de estas acumulaciones graviclásticas, el cordón está compuesto por cantos pequeños (49\%) y medios (41\%), aunque a diferencia de lo que ocurre en el borde oriental, los bloques también están representados (3\%). La talla media oscila en torno a $6,1 \mathrm{~cm}$., mientras que el centilo se eleva hasta los $65 \mathrm{~cm}$. Morfométricamente no existen diferencias significativas respecto a lo observado en el sector oriental, ya que el índice de rodamiento oscila entre 245 y 260, con un porcentaje de cantos rotos del $18 \%$, mientras que los muy rodados suponen el $19 \%$ (Edeso, 1990; Edeso \& Ugarte, 1990).

La fracción fina es inexistente. Únicamente en el sector oriental aparecen, de manera efímera, acumulaciones arenosas, cuyo origen está relacionado con momentos de aguas altas del pequeño curso cataclinal Iturraingo erreka, cuya competencia no le permite evacuar materiales de mayor talla.

Actualmente esta acumulación no se ve afectada por el oleaje, excepto durante los fuertes temporales del NW (olas por encima de los 6-7 m) que periódicamente afectan al litoral cantábrico. Su origen tampoco puede vincularse a los aportes del arroyo Iturraingo erreka, ya que este curso apenas es capaz de arrastrar sedimentos arenosos. En este paraje, y en Xixurko, existen vestigios que apuntan la posible existencia de un rudimentario embarcadero en una posición más elevada que la actual línea de costa.

\section{Ensenadas de Limaputzu y Xixurko}

En la ensenada de Limaputzu desemboca el arroyo Txortxipiko erreka, cuyo tramo final enlaza con una playa de cantos rodados y bloques, cuyo segmento superior está cubierto por un suelo y colonizado por la vegetación. Unos $180 \mathrm{~m}$ aguas arriba de la desembocadura, el río se ve obligado a salvar un pequeño desnivel vertical de $1 \mathrm{~m}$ de altura. A partir de ese punto, el valle presenta una incli- nación suave $(<0,5 \%)$ lo que favorece la deposición de los sedimentos arenosos arrastrados por el arroyo. Al margen de las acumulaciones arenosas actuales situadas en el cauce (de origen fluvio-torrencial), se observa un pequeño nivel de acumulación de $40 \mathrm{~cm}$ de potencia, constituido casi exclusivamente por arena. Esta acumulación se sitúa 2,05m por encima del máximo nivel alcanzado por la pleamar (Lopetegi et al., 2012). Las características sedimentológicas de estas arenas ponen de manifiesto su origen fluvio-marino. La fracción fina está compuesta, casi totalmente por arena (92,9 y 99,8\%), predominando las arenas medias, de ahí que la talla media oscile en torno a las $230 \mu \mathrm{m}$. Los histogramas granulométricos son unimodales, la selección buena, la skewness es simétrica, la angulosidad gráfica mesocúrtica y la curva acumulativa hiperbólica de tipo sigmoidal ligeramente tendida (sedimentación ligeramente forzada). La presencia de algunos pequeños fragmentos de concha subraya el carácter marino de la acumulación.

Las características morfométricas y granulométricas de la fracción gruesa son similares a las descritas en Marla: predominio de los cantos grandes (43\%) y medianos (33\%), aunque los bloques también están bien representados (13 cm de media y $71 \mathrm{~cm}$ el centilo); valores morfométricos similares, discreto índice de rodamiento (266), elevado porcentaje de cantos rotos (18\%), perforaciones ocasionadas por moluscos litófagos y huellas evidentes de haber sido sometidos a un intenso proceso de abrasión marina. Actualmente, el desmantelamiento erosivo (arroyada) está exhumando diversas acumulaciones de cantos y bloques que hasta ahora estaban cubiertos de materiales finos y colonizados por la vegetación (Fig. 21). El origen de todas estas acumulaciones es marino, aunque los procesos fluvio-torrenciales pueden haber introducido modificaciones significativas en las características granulométricas del sedimento.

En Xixurko se repite el mismo esquema. Es decir, el pequeño curso cataclinal de Martitxerreka también está obligado, a unos $160 \mathrm{~m}$ de su desembocadura, a salvar un pequeño desnivel de 1,5/2 m, dibujando para ello un salto vertical muy nítido. A partir de este punto, el valle está colmatado por sedimentos arenosos que acaban enlazando con una playa de cantos y bloques. El borde superior de esta playa (edafizado y colonizado por la vegetación), se caracteriza por el predominio de los cantos medios (48\%) y pequeños (29\%), aunque los bloques también están bien representados $(8 \%)(7,9 \mathrm{~cm}$ de media y $86 \mathrm{~cm}$ de centilo).

\section{Banquetas erosivas de Mintegiko erreka y Erentxun Zabal}

En la desembocadura del arroyo Mintegiko Erreka se ha modelado una pequeña banqueta erosiva de 30 por $10 \mathrm{~m}$. En este caso, no se observa ninguna acumulación detrítica, siendo tan sólo la forma topográfica la que apunta hacia un origen marino. Dicha banqueta se sitúa entre 1,5 y 2 m por encima del nivel marino actual, no viéndose afectada por el oleaje más que en situaciones de fuerte temporal. 


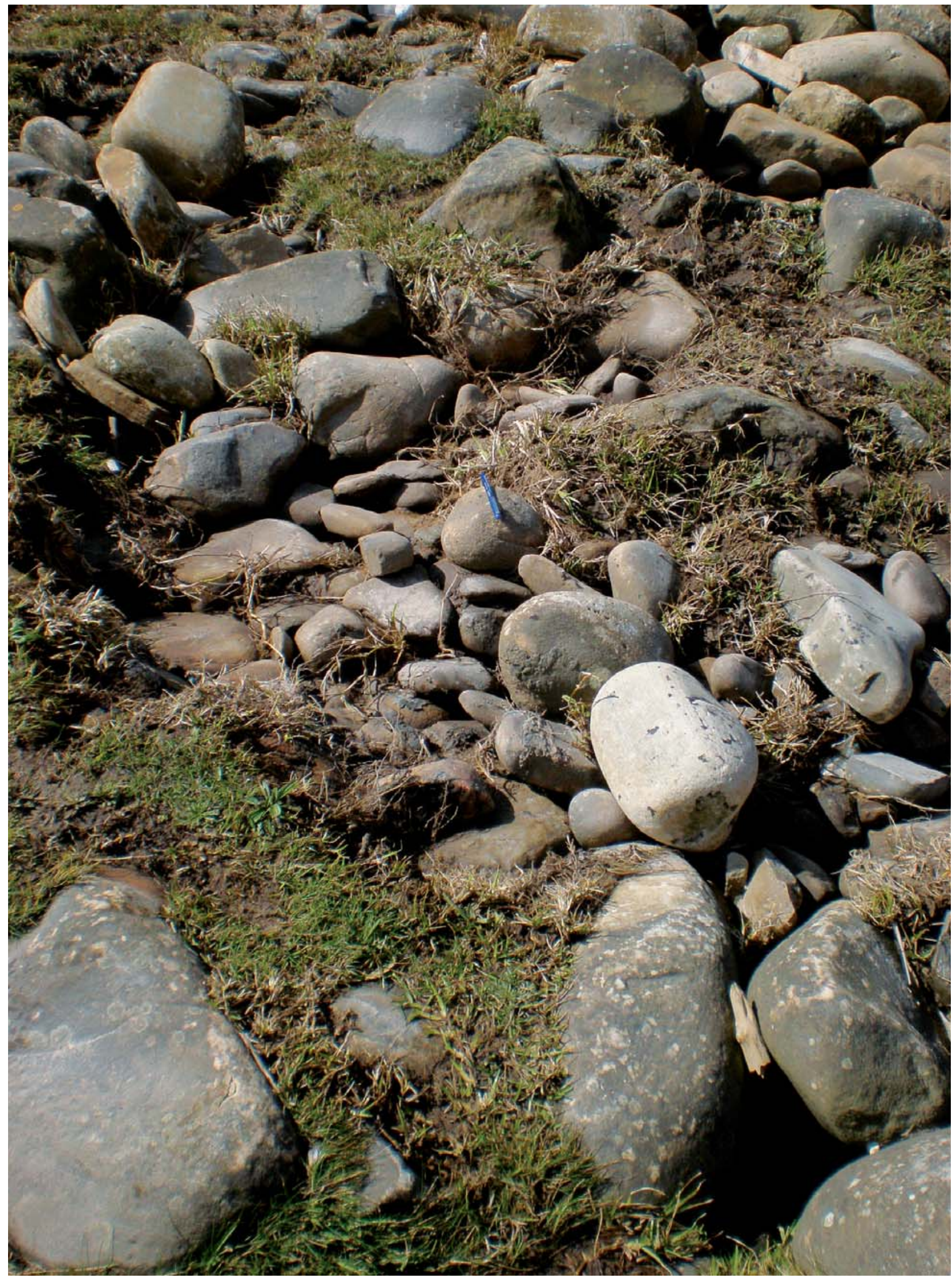

Fig. 21. - Cantos y bloques exhumados por la erosión en la pequeña cala de Limaputzu.

21. Irudia. Higadurak Limaputzuko itsasarte txikian higaduragatik azaleratutako uharriak eta harri koskorrak 
En el paraje conocido como Erentxun Zabal, se ha modelado una amplia plataforma de abrasión marina cuya parte interna está entre 0,5 y 2 m por encima del nivel marino actual (en pleamar). No existen en ella acumulaciones dignas de mención, aunque la plataforma presenta un importante modelado de pilancones, cuencos y pozas de evorsión turbillonar, generados a partir de la disolución de las paramoudras existentes en la zona.

\section{DISCUSIÓN Y CONCLUSIONES}

A lo largo del litoral vasco son escasos los niveles marinos bien documentados (González et al., 2005) y a pesar de que durante las últimas décadas esta situación ha mejorado sustancialmente, todavía estamos muy lejos de poder establecer una síntesis evolutiva coherente respecto a las variaciones experimentadas por el nivel del mar (y los movimientos epirogenéticos del margen continental) a lo largo del Pleistoceno y del Holoceno.

Se han identificado dos niveles de rasa mareal, localizados a 220-250 m el más antiguo y a 30-40 m el más reciente. Este último ha sido descrito en BilbaoPlentzia (Cearreta \& Pascual, 1990) y Bermeo-Mundaka (Llopis Lladó et al., 1957), así como diversas acumulaciones detríticas situadas a una cota similar (Arrietara, Atxibiribil, Errekalde y Barrika) que han sido interpretadas como dunas remontantes de tipo Cliff-top (Cruz San Julián et al., 1984; Edeso \& Ugarte, 1990; Cearreta et al., 1991). La ausencia de depósitos correlativos sobre la mayor parte de las rasas, junto con la falta de elementos susceptibles de ser datados, nos impide establecer una cronología absoluta para estas acumulaciones, aunque las evidencias estudiadas en territorios próximos (Asturias y Cantabria), atribuyen una cronología Pliocena y finipliocena (González et al., 2005) para los niveles situados por encima de los 220-250 m y Holsteiniense (interglaciar Mindel-Riss) para el nivel desarrollado entre los 40 y $60 \mathrm{~m}$. En la costa asturiana Mary (1983) describe 5 niveles de rasa desarrollados entre los 180-260 (coincidiría con el nivel superior de Jaizkibel), 100-180, 60-105, 35-40 (nivel bajo de Jaizkibel) y 15-18 m. Estos niveles no han podido ser datados de manera absoluta debido a la falta de fósiles, pero recurriendo a diversos criterios indirectos se les asigna una edad que va del Mioceno para el más alto, hasta el Pleistoceno medio-superior para el inferior.

Junto a las plataformas marinas se ha podido estudiar una compleja acumulación detrítica (depósito de Goizut ${ }^{4}$ ), situada altimétrica y morfológicamente en una posición similar a la de las rasas mareales anteriormente citadas. Todo ello nos permite diferenciar una serie de subambientes sedimentarios, coetáneos en el tiempo, pero que indican procesos y dinámicas hidrogeomorfológicas sumamente variadas. Así, en las zonas más expuestas se modelaron amplias plataformas de abrasión en un ambiente litoral abierto, expuesto al oleaje y muy erosivo (características similares a las que hoy encontramos en el intermareal). Sobre esta plataforma se desarrollaron diversas geoformas (vaciado de cannon-balls, pozas de evorsión turbillonar, cuencos, etc.) así como una delgada película de gravas y cantos, cuya génesis no puede vincularse a la litología del monoclinal (algunas de ellas no están presentes), ni tampoco a los aportes de los ríos periféricos (Bidasoa, Oiartzun y Urumea), por lo que hay que pensar en un origen alóctono y en una posterior removilización por las olas y corrientes marinas hasta depositarse en su posición actual.

En las zonas más protegidas hemos encontrado una secuencia deposicional que apunta hacia una paleodesembocadura, a la que podríamos añadir dos depósitos estuarinos situados en el corredor Irún-San Sebastián (Edeso, 1990; 1992; Cearreta et al., 1992). La acumulación se inicia mediante un depósito fluvio-torrencial, genéticamente vinculado al río Jaizubia, que se deposita sobre una superficie horizontal. Posteriormente se inicia una fase transgresiva que inunda estos espacios, configurándose probablemente un estuario primero y un medio francamente marino después (¿playa? ¿llanura intermareal arenosa?) que acaba evolucionando (¿progradación? ¿regresión?) hacia ambientes eólicos.

Dada la elevada altimetría de los vestigios estudiados, no podemos vincular su origen a procesos exclusivamente glacioeustáticos, siendo preciso atribuir su génesis a una combinación de mecanismos epirogenéticos y glacioeustáticos desarrollados, probablemente, desde finales del Mioceno (Mary, 1983) o Plioceno. El modelado de cada uno de estos niveles, se correspondería con un estacionamiento prolongado del nivel del mar o con estadios pasivos en la dinámica cortical que propiciaron la abrasión del sustrato (Flor, 1983).

En cualquier caso, a la hora de intentar correlacionar estos niveles con algunos de los definidos en Asturias y Cantabria hay que ser muy precavido, ya que se desconocen los datos fundamentales de la evolución tectónica post-Pliocena en la zona correspondiente a la morfo-estructura pirenaica (Edeso, 1990; Edeso \& Ugarte, 1990), así como los eventos relacionados con las oscilaciones glacioeustáticas pleistocenas. Actualmente se acepta el hecho de que no existe una curva de cambios del nivel del mar que sea de aplicabilidad mundial, y se está de acuerdo en que los controles locales y regionales son tan importantes que pueden imponer variaciones significativas en los gráficos que reflejan dichos cambios.

Aunque a lo largo del Holoceno se suceden una serie de pulsaciones transgresivas y regresivas, en el monoclinal únicamente han quedado vestigios de la última pulsación. En este sentido podemos afirmar que se han conservado una serie de formas y acumulaciones detríticas, cuyo origen se vincula a una pulsación transgresiva que ya se había producido durante la Alta Edad Media (540-690 AD). A escala regional se conocen una serie de evidencias (Mary,

${ }^{4}$ Aunque fuera de la zona de estudio pero muy próxima a ella se han analizado los depósitos de Irubide y Manziategi, probablemente de la misma cronología que Goizut. 
1979; Flor, 1983; Vilas, 1991; Edeso, 1990 etc.) que ponen de manifiesto el desarrollo de un nivel marino situado por encima del actual, aunque la horquilla cronológica obtenida por los diversos investigadores fluctúa, en fechas calibradas, entre el 420BC-170AC y el 200BC-400 AC. La datación obtenida en Plaiaundi (estuario del Bidasoa) es algo más reciente, aunque creemos que la misma es coherente con las aportadas por otros investigadores. A pesar de que no puede establecerse de manera fiable una curva de ascenso del nivel del mar en el Cantábrico, parece evidente que entre finales del primer milenio antes de Cristo y la Alta Edad Media (es entonces cuando se construyen los embarcaderos anteriormente citados) se produjo una pulsación transgresiva que situó el nivel del mar entre 1 y 2 m por encima de su posición actual.

Es posible que algunas de las formas citadas anteriormente ya hubiesen comenzado a modelarse durante alguna de las pulsaciones Holocenas anteriores (Edeso, 1990, 1994)

\section{AGRADECIMIENTOS}

El presente trabajo se enmarca dentro del proyecto HAR2011-26956 del Ministerio de Ciencia e Innovación.

\section{BIBLIOGRAFÍA}

Bertrand, P., Allenet, G., Gé, T., Poirier, T., Sánchez Goñi, M.F. 2009 Conversand and Pleistocene palaeosols in the Landes region, southwestern France. J. Quat. Sci. 24 (3) :259-269.

Cailleux, A. 1959. Initiation à l'étude des sables et des galets. Ed. Sedes. París.

Cailleux, A., Tricart, J. 1963. Initiation l'étude des sables et des galets. Centre de Documentation Universitaire de París.

Campos, J. 1979. Estudio geológico del Pirineo al Oeste del río Bidasoa. Munibe 31(1-2): 3-139

Cearreta, A., Pascual, A. 1990. Estudio micropaleontológico de los depósitos cuaternarios litorales situados entre Laredo e Ibarrangelua (Cantabria y Bizkaia). Actas de la $2^{a}$ Reunión del Cuaternario Ibérico. Madrid.

Cearreta, A., Edeso, J.M., Ugarte, F.M. 1992. Cambios del nivel del mar durante el Cuaternario reciente del Golfo de Vizcaya. In The Late Quaternary in the Western Pyrenean Region. A. Cearreta, F.M. Ugarte (Ed.). Universidad del País Vasco. Bilbao.

Corrales, I., Rossell, J., Sánchez, L., Vera, J.A., Vilas, L. 1979. Estratigrafía. Ed. Rueda. Madrid.

Cruz San Julián, J.J., García-Mondejar, J., Granda, J.M., Pujalte, V. 1984. Características y evolución de unos depósitos de Cliff-topp localizados sobre la rasa costera vizcaína. Thalassas 2: 31-34.

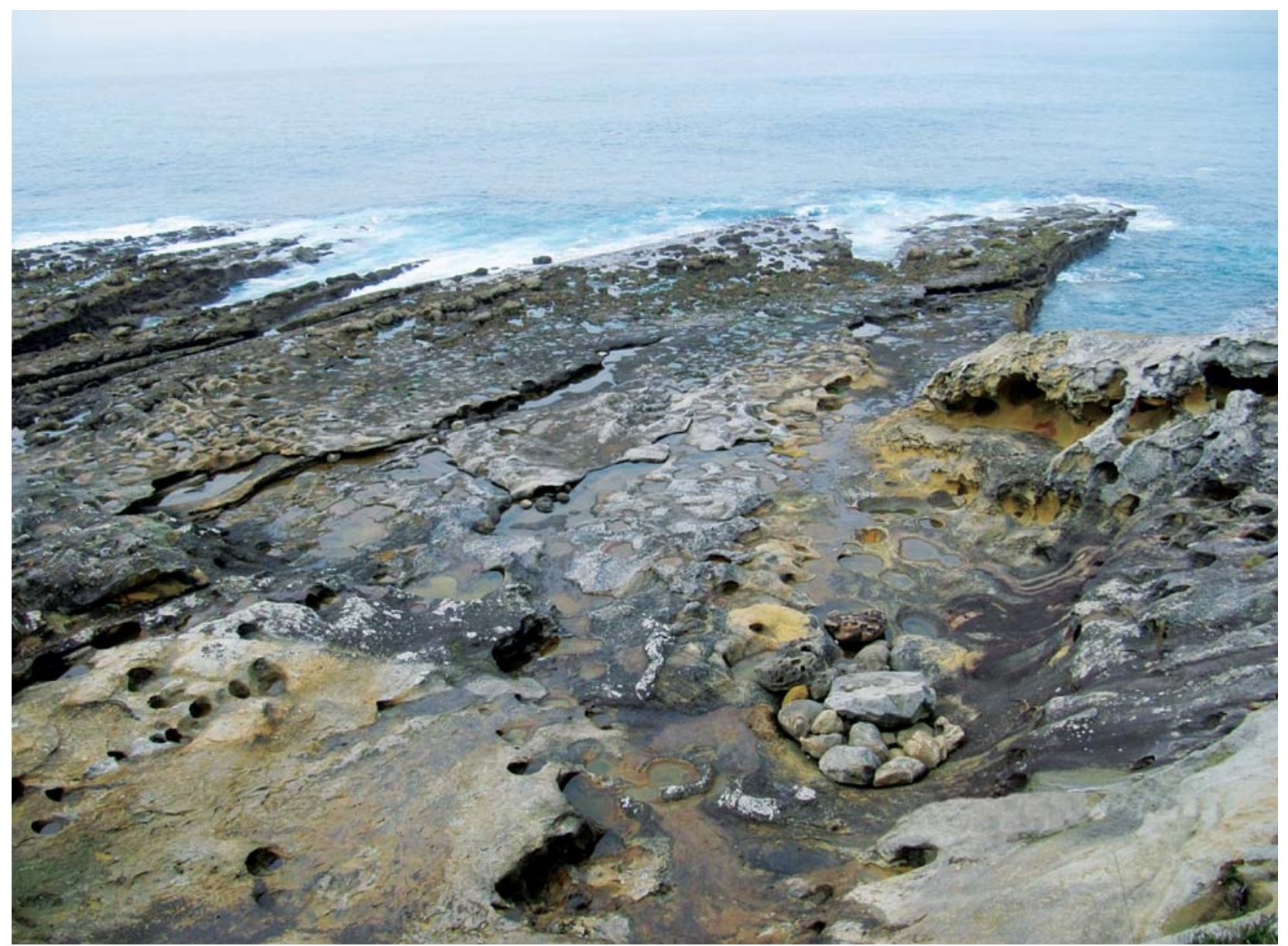

Fig. 22. - Plataforma de abrasión marina de Erentxun Zabal (a media marea).

22. Irudia. Erentxun Zabaleko itsas urradura plataforma (marea erdi aldean). 
Edeso, J.M. 1990. Geomorfología fluvial y litoral del extremo oriental de Gipuzkoa. Tesis Doctoral (inédita). Universidad de Zaragoza. Zaragoza.

Edeso, J.M. 1991. Variaciones del nivel del mar en el País Vasco durante el Holoceno. Bol. Asoc. Geógraf. Esp. 13: 21-44.

Edeso, J.M. 1992. Variaciones del nivel del mar durante el Pleistoceno Medio (Extremo Oriental de Guipúzcoa. País Vasco). Lurralde 15: 63-106.

Edeso, J.M. 1994. El relleno Holoceno de la depresión de Zarauz. Lurralde 17: 115-152.

Edeso, J.M., Ugarte, F.M. 1990. Algunos datos sobre la Paleo-Geografía litoral Cuaternaria de la costa: Jaizkibel-Bahía de Txingudi (Golfo de Vizcaya). Cuadernos de sección. Historia-Geografía 16: 27-76.

Edeso, J.M., Ugarte, F.M., Peñalba, C. 1993. El depósito detrítico pleistoceno de Anzaran (Irún, estuario del Bidasoa). Actas de la II Reunión de Cuaternario Ibérico. Madrid: 191-199.

Edeso, J.M., Mujika-Alustiza, J.A. 2005. El entorno de Zarautz durante el Cuaternario. Evolución paisajística, ambiental y humana. Museo de Arte e Historia de Zarautz. Zarautz.

Edeso, J.M. 2007. Caracterización geomorfológica de diversos depósitos coluviales localizados en la cabecera del río Oiartzun (Gipuzkoa). Lurralde 30: 95-107.

Edeso, J. M. 2006. Caracterización granulométrica, morfométrica, litológica y sedimentológica de las terrazas fluviales del valle del río Oiartzun (Guipúzcoa, País Vasco). Lurralde 29: 299-342.

Flor, G. 1983. Las rasas asturianas: ensayos de correlación y emplazamiento. Trab. Geol. 13: 65-81.

Folk, R.L., Ward, W. 1957. Brazos River Bar: a study on the significance of grain size parameters. Sediment. Petrol. 27: 3-26. Garrote, A., García, P., Muñoz, L., Fernández, J., Cerezo, A., Tijero, F., Zapata, M. 1990. Mapa Geológico del País Vasco. 64-II. San Sebastián. E: 1/25.000. Vitoria-Gasteiz.

Gibbons, W., Moreno, T. 2002. The Geology of Spain. The Geological Society. Londres.

Gómez de Llarena, J. 1960. Observaciones fisiográficas en el litoral de Guipúzcoa. I. La plataforma de abrasión o rasa mareal. Sociedad Oceanográfica de Guipúzcoa. San Sebastián.

González, M. J., Serrano, E., Edeso, J.M., Meaza, G. 2005. Cambios en el nivel del mar durante el Cuaternario en el País Vasco y Cantabria. En: Geomorfología litoral i Quaternari. Homenatge al profesor Vicenç M. Roselló I Verger. E. Sanjaume, J.F. Mateu (Ed.):167-180.

Hodgson, D.M., Wild, R.J. 2006. Facies and architecture of the Lezonabar Member Higuer-Getaria Formation, Guipuzcoa Basin, NE Spain. In: Atlas of Deepwater Reservoirs American Association of Petroleum Geologist T. Nilsen, R. Shew, G. Steffens, J. Studlick J. (Ed.):1-8. American Association of Petroleum Geologists. Tulsa, Okla.
Lopetegi, A., Edeso, J.M., Mujika-Alustiza, J.A. 2012. Niveles transgresivos recientes entre las desembocaduras del Bidasoa y de Oiartzun-Bahía de Pasajes (Gipuzkoa). Avances de la Geomorfología en España 2010-2012. Actas de la XII Reunión Nacional de Geomorfología. Santander : 331-335.

Llopis Lladó, N., Jorda, F., Martínez-Álvarez, J.A. 1957. LivretGuide de l'Excursion № 2. Le quaternaire de la Région Cantabrique. INQUA V Congreso Internacional. Oviedo.

Mary, G. 1979. Evolution de la bordure côtière asturienne (España) du Néogène à l'actuel. Thèse de Doctorat d'État. Université de Caen.

Mary, G. 1983. Evolución del margen costero de la Cordillera Cantábrica en Asturias desde el Mioceno. Trab. Geol.13 : 3-35.

Mary, G. 1990. La evolución del litoral cantábrico durante el Holoceno. Proceedings of the International Conference on the Environment and the Human Society in the Western Pyrenees and the Basque Mountains during the Upper Pleistocene and the Holocene: 81-87.

Mary, G. 1992. Interacción entre la Epirogénesis y el Eustatismo en el escalonamiento de las áreas de abrasión marina Neógenas y Pleistocenas del segmento medio de la costa Norte Española. Cuad. Sec. Historia 20: 135-150.

Merino, J.M. 1986. Yacimiento de Cabo Higuer en el monte Jaizkibel (Fuenterrabía). Munibe 38: 61.94

Miall, Andrew D. 1977. Fluvial sedimentology. Can. Soc. Petrol. Geol.

Moñino, M., Díaz Teran, J.R., Cendrero, A. 1987. Variaciones del nivel del mar en la costa de Cantabria durante el Cuaternario. Actas de la VII Reunión sobre el Cuaternario. Santander: 223-236.

Pujalte, V., Robles, X., Orue-Etxeberria, J., Baceta, A., Larruzea, F. 2000. Uppermost Cretaceous-Middle Eocene strata of the Basque-Cantabrian Region and Western Pyrenees: A sequence stratigraphic perspective. Rev. Soc. Geol. Esp. 13(2): 191-211.

Rivas Mantecon, V. 2000. Clima y nivel del mar: reconstrucción de las posiciones marinas Cuaternarias a través de las evidencias en el litoral Cantábrico. En: La reconstrucción del clima de época preinstrumental: V Reunión Nacional de Climatología. J.C. García Codrón (Coord.): 179-205. Universidad de Cantabria.

Santana, 9. 1966. Géomorphologie des bassins de la Bidasoa et de I'Urumea. Thèse de Doctorat. Université, Institut de Géographie. Bordeaux.

Ugarte, F. M., Edeso, J.M. 1987. Primeros datos sobre el paleopaisaje litoral Cuaternario del golfo de Vizcaya (Bidasoa-Urumea). VII reunión nacional de Cuaternario. Santander: 249-252.

Vilas, F. 1991. The Corrubedo beach-lagoon complex, Galicia Spain. Dynamics, sediments and recent evolution of a mesotidal coastal embayment. Mar. Geol. 97: 391-404. 